\title{
Nowcasting, forecasting and warning for ionospheric propagation: tools and methods
}

\author{
RICHARD STAMPER $\left({ }^{1}\right)$, ANNA BELEHAKI $\left({ }^{2}\right)$, DALIA BUREŠOVÁ $\left({ }^{3}\right)$, LJILJANA R. CANDER $\left({ }^{1}\right)$, \\ IVAN KUTIEV $\left({ }^{4}\right)$, MARCO PIETRELLA $\left({ }^{5}\right)$, IWONA STANISLAWSKA $\left({ }^{6}\right)$, STANIMIR STANKOV $\left({ }^{7}\right)$, \\ IOANNA TSAGOURI $\left({ }^{2}\right)$, YURDANUR K. TULUNAY $\left({ }^{8}\right)$ and BRUNO ZOLESI $\left({ }^{5}\right)$ \\ (') Rutherford Appleton Laboratory, Chilton, Didcot, Oxon, U.K. \\ (2) National Observatory of Athens, Institute for Space Applications and Remote Sensing, P. Penteli, Greece \\ $\left(^{3}\right)$ Institute of Atmospheric Physics, Academy of Science of Czech Republic, Prague, Czech Republic \\ $\left({ }^{4}\right)$ Bulgarian Academy of Sciences, Sofia, Bulgaria \\ $\left({ }^{5}\right)$ Istituto Nazionale di Geofisica e Vulcanologia, Roma, Italy \\ $\left.{ }^{6}\right)$ Space Research Centre, Warsaw, Poland \\ (7) Deutsches Zentrum für Luft und Raumfahrt (DLR), Institut für Kommunikation und Navigation (IKN), \\ Neustrelitz, Germany \\ $\left({ }^{8}\right)$ Istanbul Technical University, Istanbul, Turkey
}

The paper reviews the work done in the course of the COST 271 Action concerned with the development of tools and methods for forecasting, nowcasting and warning of ionospheric propagation conditions. Three broad categories of work are covered. First, the maintenance and enhancement of existing operational services that provide forecast or nowcast data products to end users; brief descriptions of RWC Warsaw and the STIF service are given. Second, the development of prototype or experimental services; descriptions are given of a multi-datasource system for reconstruction of electron density profiles, and a new technique using real-time IMF data to forecast ionospheric storms. The third category is the most wide-ranging, and deals with work that has presented new or improved tools or methods that future operational forecasting or nowcasting system will rely on. This work covers two areas - methods for updating models with prompt data, and improvements in modelling or our understanding of various ionospheric-magnetospheric features - and ranges over updating models of ionospheric characteristics and electron density, modelling geomagnetic storms, describing the spatial evolution of the mid-latitude trough, and validating a recently-proposed technique for deriving TEC from ionosonde observations.

\subsection{INTRODUCTION}

One of goals of the entire COST 271 Action is to support the better use of radiocommunications systems that are affected by the variability of the ionosphere, and in particular to allow for the less predictable component of that variation that is due to the constantly changing space weather environment. A key method for addressing this goal is to provide end-users with easy access to robust forecasting and warning systems that enable them to plan more effectively how to cope with this variation. This paper outlines some of the wide variety of work that has been carried out during the course of the Action 
in developing nowcasting and forecasting procedures, with a particular focus on making use of prompt data. This ranges from fully functional operational services, through prototype and experimental systems, to more basic work on developing and improving algorithms for handling data and making forecasts.

\subsection{Operational Services}

Operational services that forecast and warn of ionospheric conditions are an immediate and practical form of support to users of radiocommunications systems affected by the ionosphere. The role of a service provider entails many tasks which, though possibly mundane, are essential to providing a worthwhile service. In particular, the flows of data into the system, the software, and the computing and networking hardware all have to be administered, maintained and in some cases replaced. The two leading examples of such services within the COST 271 Action were first established during the previous COST 251 Action, and have been maintained and enhanced during the course of the present action. They are the Regional Warning Centre Warsaw, and the Short-Term Ionospheric Forecasting service.

\subsubsection{RWC Warsaw}

One of the outcomes of the COST 251 Action was the establishment of the Regional Warning Centre (RWC) Warsaw as one component of the network of Regional Warning Centres which together form part of the International Space Environment Service, ISES. This service has now been maintained by the Space Research Centre (SRC) Warsaw, for the duration of the COST 271 Action. Received data are either relayed from other Warning Centres around the world or obtained directly from observatories and other regional and global data providers. A wide range of data services are offered describing the solar, geomagnetic and ionospheric conditions, and including catalogues of past events, descriptions of recent and current conditions, and forecasts of future conditions. Most are accessible via the RWC web site at http://www.cbk.waw.pl/rwc/rwc.html/.

The services are provided by a combination of textual and graphical reports, as appropriate. Various solar and geomagnetic data products provide contextual information for understanding the ionospheric propagation conditions. An example solar report and forecast is shown in fig. 3.1a, which includes predictions of the conditions to be observed at a number of solar observatories around the world. The RWC also provides many products that describe and predict the ionosphere directly. Maps of the F2-layer critical frequency $f o F 2$ over the previous $24 \mathrm{~h}$ are generated daily using reports from a network of ionosondes (fig. 3.1b); an extension to this service provides forecasts of the foF2 parameter, either for a particular station or for a region. Forecasts for $24 \mathrm{~h}$ ahead can be accessed in graphical or textual formats via an index page or a selection map, and an example of a regional map can be seen in fig. 3.1c. All of these forecasts are based on work by the SRC on producing point forecasts of foF 2 (Stanisławska and Zbyszyńs$\mathrm{ki}, 2001)$. In addition to forecasting ionospheric parameters, the RWC web site also makes available maps of the signal-to-noise ratio for propagation paths to and from Warsaw for a range of transmission frequencies. Figure 3.1d gives an example of these maps for a $15 \mathrm{kHz}$ signal being transmitted from Warsaw and shows the expected signal-to-noise ratio for receiving this signal anywhere worldwide, varying according to time of day. These maps are based on median conditions and are updated monthly.

\subsubsection{STIF}

A second operational service that had been established by the time of the completion of the COST 251 Action was the Short-Term Ionospheric Forecasting (STIF) tool for the European region, 


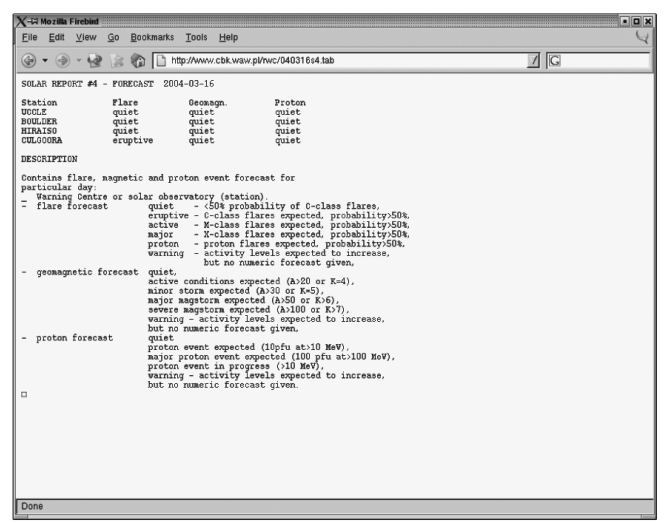

(a)

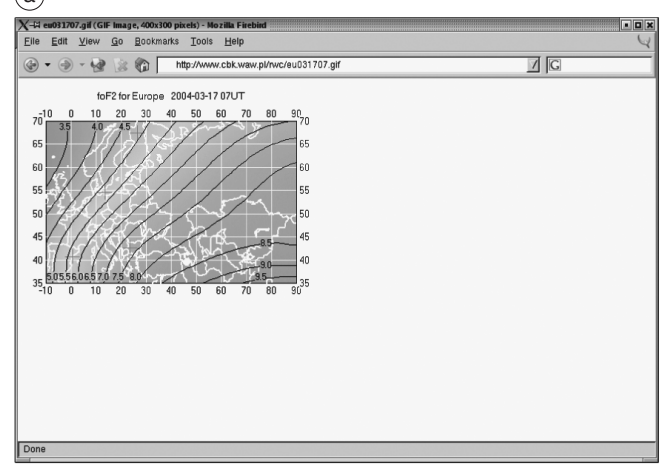

(C)

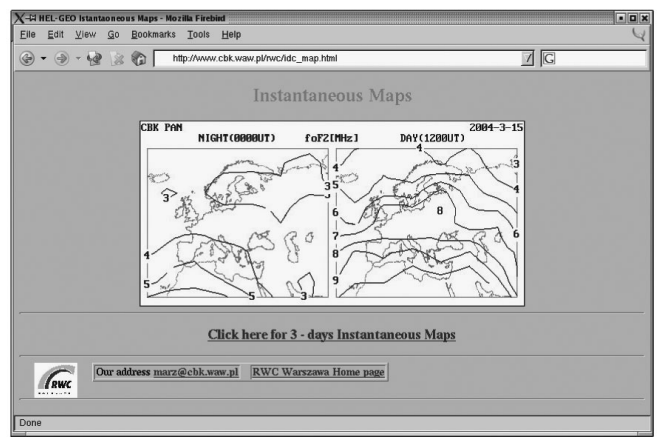

(b)

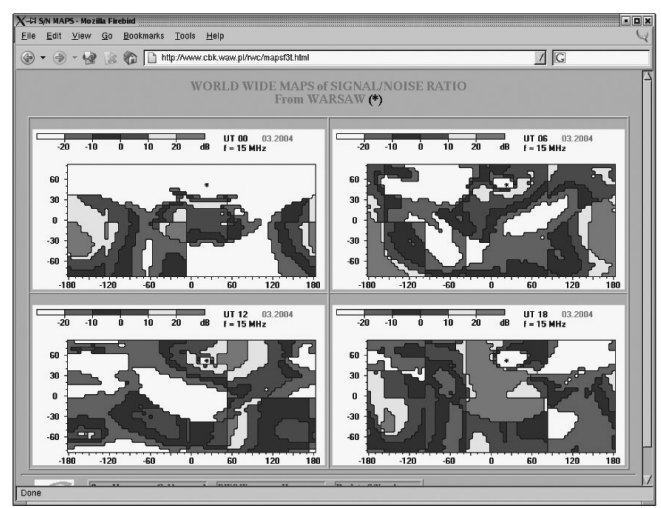

(d)

Fig. 3.1a-d. Example data products available from the RWC Warsaw web site. a) A solar forecast for 16.03.2004; b) maps of recent $f o F 2$ for 15.03 .2004 ; c) a forecast map of $f o F 2$ for 17.03.2004; d) predicted global signal-to-noise ratio maps for a $15 \mathrm{kHz}$ signal transmitted from Warsaw in March 2004.

provided by the Radiocommunications Research Unit (RCRU) at the Rutherford Appleton Laboratory (RAL) in the U.K. This tool, and the supporting network of contributing ionosonde stations, has been maintained during the COST 271 Action with the underlying software all having been revised and ported to new computer systems for greater reliability. The STIF service provides maps of both archived measurements and forecasts up to $24 \mathrm{~h}$ ahead of the critical frequency $f_{O} F 2$, the Maximum Usable Frequency for a $3000 \mathrm{~km}$ range $\operatorname{MUF}(3000) F 2$, Total Electron Content (TEC) and Frequency of Optimum Traffic (FOT) for the European area at each UT hour (Cander, 2003; Cander et al., 2003). Examples of the foF 2 and TEC forecast maps can be seen in fig. 3.2.

This initial offering now forms only part of a more comprehensive range of services, titled the 'Space Weather Web Facilities for Radio Communications Users', and available on-line as a 24/7 service at http://ionosphere.rcru.rl.ac.uk/. In addition to the STIF products, there are also vertical TEC values derived from the ITU-R recognised NeQuick ionospheric model and vertical TEC values evaluated from RINEX files of the International GPS Service for Geodynamics (IGS) (Cander and Ciraolo, 2002). Data are processed automatically several times daily and displayed in a variety of modes - contour maps for Europe nowcasting and forecasting up to $24 \mathrm{~h}$ ahead for foF 2 , MUF(3000)F2 and TEC; animated contour maps for the last $24 \mathrm{~h}$, daily plots from each station. 

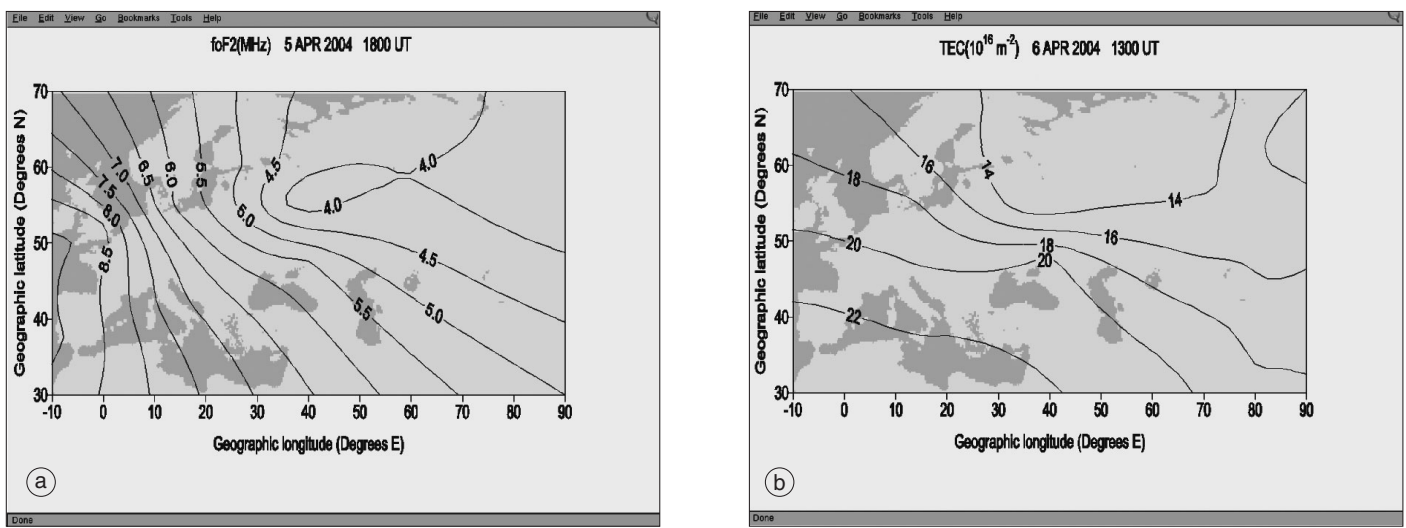

Fig. 3.2a,b. Example maps from the web site of the STIF tool at RAL. a) Forecast of $f o F 21 \mathrm{~h}$ ahead; b) forecast of derived TEC $20 \mathrm{~h}$ ahead.

There is also an archive of measured data and space weather warnings and bulletins from NOAA in the US and from other sources.

This range of services clearly depends on other supporting services and on a range of technical and scientific developments. These include: a Europe-wide network of vertical ionosondes contributing in near-real-time either directly or via the COST 271 database; a Europe-wide network of GPS receivers providing near-real-time data access; the development of robust short-term forecasting algorithms for foF $2, M(3000) F 2$, TEC to predict up to at least $24 \mathrm{~h}$ ahead; development of a mapping algorithm for interpolation between the stations and GPS sites in the networks as used by the instantaneous mapping procedure; validation of the mapping and forecasting algorithms. This variety of inputs and supporting techniques is typical of any operational service dealing with dynamic changes in propagation conditions.

\subsection{EXPERIMENTAL SERVICES}

Before an operational service can be regarded as mature it will necessarily have passed through a phase of experimentation and prototyping. When a service is in this preliminary phase it may be of some operational use, but its prime purpose should be regarded as demonstrating the potential application of new insights into the physics of the solar-terrestrial system, as they affect radiocommunications. Two examples are covered here, one looking at the influence of solar wind on ionospheric disturbances and the other constructing electron density profiles using ionosonde and GPS-TEC data.

\subsubsection{Solar wind drivers of ionospheric disturbances}

Even from the very early days of ionospheric research the connection was made between the ionospheric disturbances causing disruptions in HF communications systems and enhanced geomagnetic activity. More recent studies gave evidence that the night time ionospheric response at middle latitudes is strongly dependent on the particular conditions during which solar wind/magnetosphere coupling occurred (Belehaki and Tsagouri, 2002b). According to these studies, a point of great importance is the rate at which solar wind energy enters the magnetosphere/ionosphere system, which is reflected in the 
rate of change of IMF- $B z$. Until recent years such knowledge was not of operational significance because the in situ observations of the interplanetary medium were relatively sparse and intermittent. This situation has now changed radically by the presence of solar monitoring spacecraft at the $L 1$ point.

The NASA Advanced Composition Explorer (ACE) is in a halo orbit around the $L 1$ point between the Earth and the Sun and performs measurements over a wide range of energies and nuclear masses, under all solar wind flow conditions. The ACE data have been, and continue to be, fundamental in enabling the development of accurate forecasting techniques, and the consequent possibility of issuing warnings of major geomagnetic disturbances and their possible effects on the ionosphere. Under typical solar wind conditions there is roughly a one hour time delay for the solar wind to travel from the $L 1$ point to the Earth, making the data from ACE a useful input to real-time monitoring and forecasting of ionospheric and trans-ionospheric propagation conditions.

To support a real-time dynamic system for monitoring ionospheric propagation conditions over Europe an automatic retrieval system was set up to fetch:

- real-time solar wind data from the ACE data page at http://sec.noaa.gov/Data/;

- ionospheric characteristics for ionospheric sounders operating in real-time in Europe from the COST 271 database at RAL (http://www.wdc.rl.ac.uk/cgi-bin/digisondes/costdatabase.pl).

Prompt values of $f_{O F}, M(3000) F 2$ and IMF- $B z$ data are used to provide information on ionospheric propagation conditions over Europe and an automated data analysis runs at 30 min intervals at RAL (Cander et al., 2004) and can be viewed on the web at http://ionosphere.rcru.rl.ac.uk/.

An example of the information presented is given in fig. 3.3. This figure shows the modified IMF$B z$ rate of change $(d B z \bmod =100 \mathrm{dBz} / \mathrm{dt})$ over the preceding $30 \mathrm{~min}$, with the corresponding percentage deviation $d f o F 2$ of $f o F 2$ from the median, and the percentage deviation $d m F 2$ of $M(3000) F 2$ from the median. This information is presented for three ionosondes: Juliusruh, Rome and Athens (see table 3.I for details) where data were available during the relevant time intervals. Median values are calculated over the previous 30 days at 30-min intervals through $24 \mathrm{~h}$. The markers on the graph represent the measured data, and when no data are available a cubic spline interpolation is used.

There is a clear response in the F2-layer ionisation, as expressed by $d f o F 2$, to the sudden and significant changes of the IMF- $B z$ as expressed by $d B z$ mod. This is visible at all three ionospheric stations, although the details vary between stations. A few hours after $d B z$ mod changes from $+40 \%$ to $-40 \%$, the $d f o F 2$ at Juliusruh revealed a huge negative response of more than $60 \%$ below the median values. At Rome and Athens an increase of about $30 \%$ relative to the median values appeared immediately after the drastic variation in $d B z$ mod, followed by a decrease five hours later. The negative ionospheric disturbance started on 17 September 2003 and was dominant for more than $24 \mathrm{~h}$. Although not so pronounced, a negative effect has been identified in $d m F 2$ variations that have significant implications for the Maximum Usable Frequency (MUF) and Optimum Working Frequency (FOT).

A significant aspect of this example, as with many others, is that it does not correspond to geomagnetic storm conditions, as indicated by the geomagnetic indices at http://sidc.oma.be/. This implies that the observed depletions in the ionospheric $F$-region were caused by drastic disturbances in IMF and consequently they could not be predicted by any of the classical forecasting methods using geomagnetic indices as storm precursors. This demonstrates the importance of this new tool for operational ionospheric and trans-ionospheric radio systems since it enables extreme conditions to be quantified so that likely variability bounds can be defined, which is of particular importance for telecommunications planning.

The web facility is available for both operational purposes and scientific studies and will be extended to use real-time data from digisondes worldwide as requested by users. Future developments will include the introduction of other solar wind parameters from ACE, such as the rate of change of solar wind number density $(d n / d t)$ and the rate of change of solar wind bulk flow velocity $(d U / d t)$. Furthermore, statistical analysis of the outputs could help in modelling and short-term forecasting of the ionospheric response during storm conditions. This is important for the reliable performance of technologically advanced radiocommunications systems under disturbed propagation conditions (Johnson et al., 1997). 

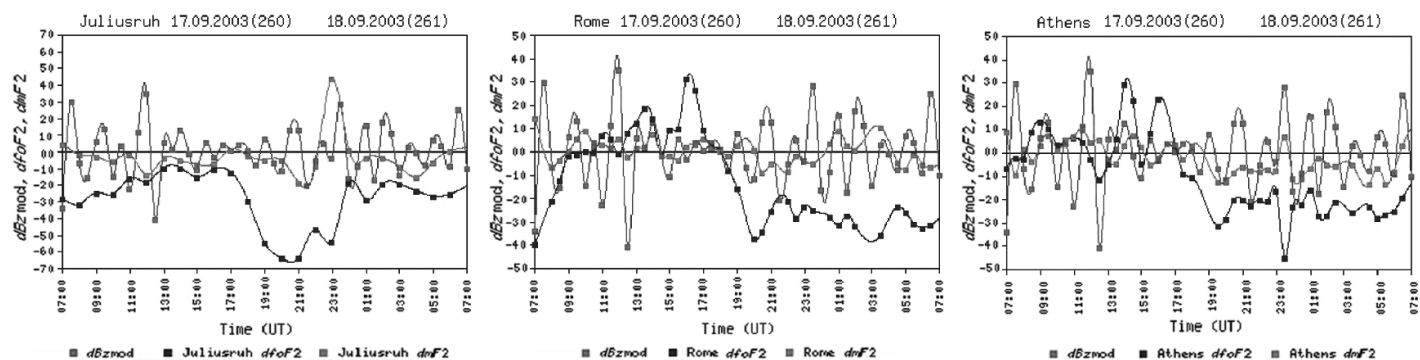

Fig. 3.3. IMF- $B z$ rate of change from the ACE spacecraft, with $d f o F 2(\%)$ and $d m F 2(\%)$ for the ionosonde stations at Juliusruh, Rome and Athens during the $24 \mathrm{~h}$ from 07:00 UT on 17.09.2003 to 07:00 UT on 18.09.2003.

Table 3.I. Ionosonde stations. The ISWILM and IRI-2000 columns indicate the use made of data from the stations in the studies described in sections respectively.

\begin{tabular}{|c|c|c|c|c|c|}
\hline Station name & Code & Latitude & Longitude & ISWILM & IRI-2000 \\
\hline Athens & AT138 & $38.0 \mathrm{~N}$ & $23.6 \mathrm{E}$ & & \\
\hline Chilton & RL052 & $51.5 \mathrm{~N}$ & $359.4 \mathrm{E}$ & $\mathrm{R}$ & $\mathrm{X}$ \\
\hline El Arenosillo & EA036 & $37.1 \mathrm{~N}$ & $353.7 \mathrm{E}$ & & $\mathrm{X}$ \\
\hline Juliusruh & JR055 & $54.6 \mathrm{~N}$ & $13.4 \mathrm{E}$ & $\mathrm{T}$ & $\mathrm{X}$ \\
\hline Kiruna & KI167 & $67.8 \mathrm{~N}$ & $20.4 \mathrm{E}$ & $\mathrm{T}$ & \\
\hline Loparskaya & LS168 & $69.0 \mathrm{~N}$ & $33.0 \mathrm{E}$ & $\mathrm{R}$ & \\
\hline Lycksele & LY164 & $64.6 \mathrm{~N}$ & $18.8 \mathrm{E}$ & $\mathrm{R}$ & \\
\hline Pruhonice & PQ052 & $50.0 \mathrm{~N}$ & $14.6 \mathrm{E}$ & & $X$ \\
\hline Rome & RO041 & $41.9 \mathrm{~N}$ & $12.5 \mathrm{E}$ & $\mathrm{R}$ & $\mathrm{X}$ \\
\hline Sodankyla & SO166 & $67.4 \mathrm{~N}$ & $26.6 \mathrm{E}$ & $\mathrm{R}$ & \\
\hline Tortosa/Ebre & EB040 & $40.8 \mathrm{~N}$ & $0.5 \mathrm{E}$ & $\mathrm{T}$ & $\mathrm{X}$ \\
\hline Uppsala & UP158 & $59.8 \mathrm{~N}$ & $17.6 \mathrm{E}$ & $\mathrm{T}$ & \\
\hline Warsaw & MZ152 & $52.1 \mathrm{~N}$ & $21.1 \mathrm{E}$ & & $\mathrm{X}$ \\
\hline
\end{tabular}

Currently available ionospheric forecasting models have shown a high degree of reliability during quiet conditions but they have proven inadequate during storm events (Cander, 2003). By tackling this difficult problem this work has the potential to make an important contribution to the effectiveness of radiocommunications systems.

\subsubsection{Real-time reconstruction of full electron density profiles}

Another prototype operational service developed during the COST 271 Action is concerned with the construction of electron density profiles, based on a novel reconstruction technique that uses various types of concurrent observations - GPS-TEC, ionosonde and direct satellite observations (Stankov et al., 2003a,b).

The vertical electron density profile at a given location is deduced from ground-based measurements of the total electron content, ionospheric vertical soundings, and empirically-obtained values of the Upper Transition Level (UTL) - the height at which the $\mathrm{O}^{+}$and $\mathrm{H}^{+}$ion densities are equal. The retrieval of the corresponding electron density distribution is performed in two main stages: con- 
struction of the bottom-side electron profile (below the F2-layer height, $h m F 2$ ) and construction of the top-side profiles (above $h m F 2$ ).

The ionosonde measurements are used primarily for obtaining the bottom-side profile, since digital ionosondes permit the deduction of profiles from about $60 \mathrm{~km}$ up to $h m F 2$. Another option which can be used here is to represent the bottom-side profile as a composition of two ( $F 2$ and $E$ ) Epsteintype layers by using $f o F 2$, $f o E, M(3000) F 2$, and $h m F 2$. Once the bottom-side profile is obtained the corresponding bottom-side electron content, TECb, is calculated. Having TEC and TECb, the topside electron content TECt $=\mathrm{TEC}-\mathrm{TECb}$, is used in the next stage for deducing the top-side profiles.

The top-side profile is permitted to take one of several forms (Stankov, 2002), as follows:

$$
\begin{array}{lr}
N_{e}(h)=N_{\mathrm{O}^{+}}(h m) \operatorname{sech}^{2}\left(\frac{h-h m}{2 H_{\mathrm{O}^{+}}}\right)+N_{H^{+}}\left(h_{m}\right) \operatorname{sech}^{2}\left(\frac{h-h m}{32 H_{\mathrm{O}^{+}}}\right) & \text {(Sech -squared) } \\
N_{i}(h)=N_{i}(h m) \exp \left(-\frac{h-h m}{H_{i}}\right) & \text { (Exponential) } \\
N(h)=N(h m) \exp \left(c\left(1-\frac{h-h m}{H}-\exp \left(-\frac{h-h m}{H}\right)\right)\right) . & \begin{array}{l}
(c=0.5, \alpha \text {-Chapman) } \\
(c=0.5, \beta \text {-Chapman) }
\end{array}
\end{array}
$$

Each of these forms can be rearranged to a transcendental equation with a single unknown, the oxygen scale height $H_{\mathrm{O}^{+}}$, provided the UTL and the top-side TEC, TECt, are known. The UTL is found from a model based on satellite and rocket measurements and parametrised by Solar activity, season, local time, latitude and longitude (Stankov et al., 2002); the TECt value is obtained from GPS-TEC measurements and the bottom-side TEC, TECb. Evaluation of these different forms of top-side profiles revealed that the Exponential layer was the best representation of day-time conditions, with the sech-squared or Chapman layers giving better results for night-time.

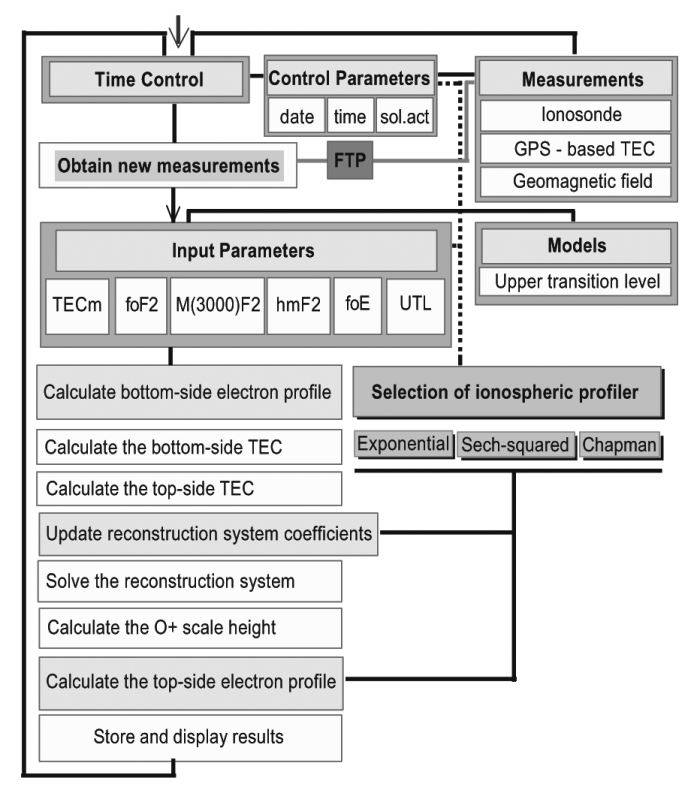

Fig. 3.4. Procedure for real-time reconstruction of the electron density profile. 
The selection of the appropriate top-side profile is now included in the prototype operational system, illustrated by the block diagram of fig. 3.4. The production of electron density profiles is triggered either by a time controlled system or by the arrival of a new measurement data block, with most of the required data being received or fetched automatically using the File Transfer Protocol. The necessary UTL value is provided by an empirical model which is a part of the reconstruction software. If some observations are not available in time there are, in some cases, fallback substitutes. For example, if the GPS-TEC value is not available, it is possible to use an ionosondederived TEC value. Data from the latest digital ionosondes can be available within 5 min of a sounding being taken; the greatest delay is therefore typically caused by the need for sufficient measurements and processing to derive the GPS-TEC value, which can take about $15 \mathrm{~min}$.

The profiler system has been tested with actual hourly values of GPS-TEC and ionosonde measurements acquired in real-time mode at the Geophysics Centre of the Royal Meteorological Institute of Belgium. A trial run covered the period from 00:00 LT on 11 March 2002 to 24:00 on 17 March 2002.
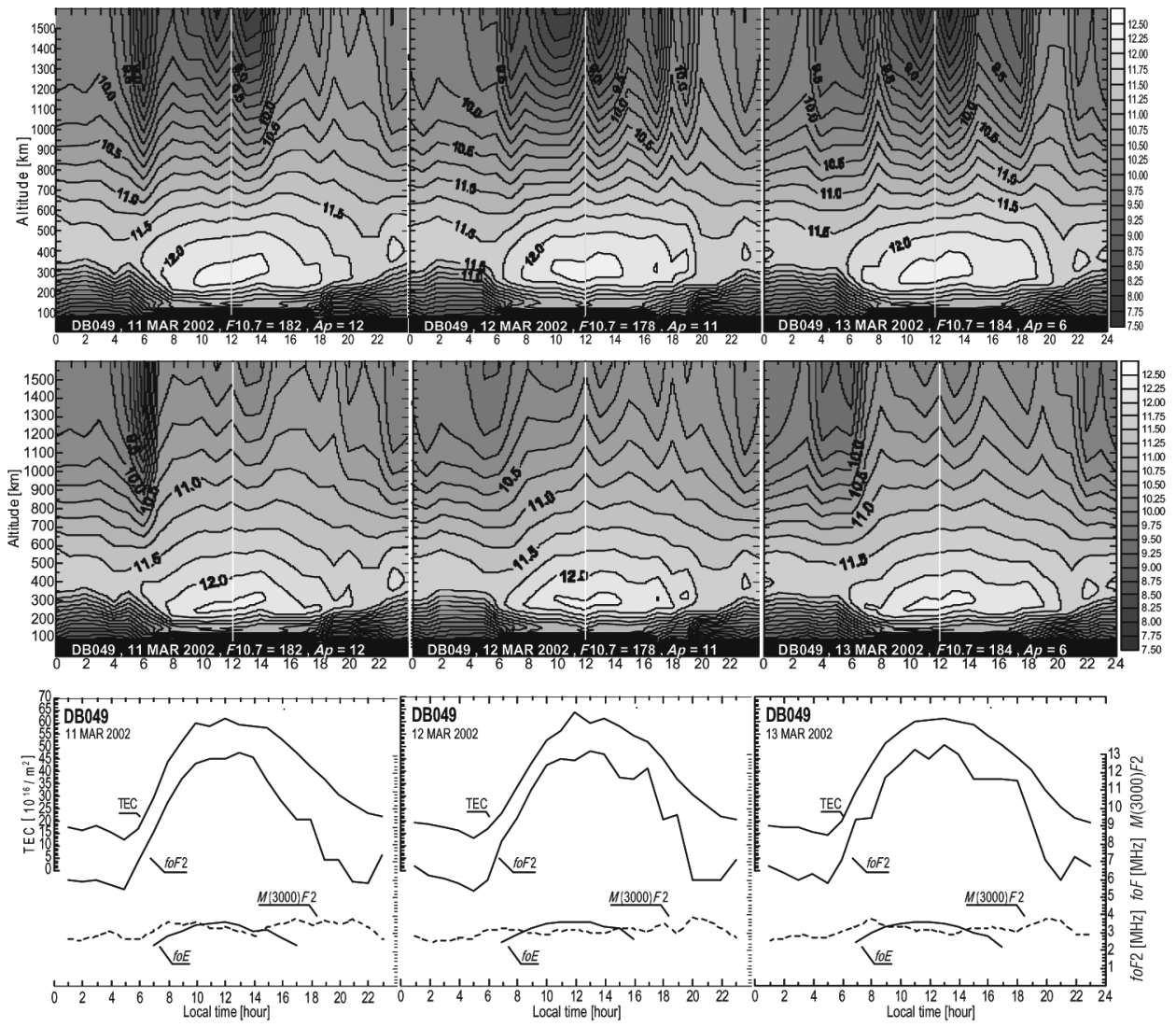

Fig. 3.5. Real-time reconstruction of the electron density profiles, 11-13 March 2003, Dourbes $\left(4.6^{\circ} \mathrm{E}\right.$, $\left.50.1^{\circ} \mathrm{N}\right)$. Top panels: reconstruction using the Sech-squared profiler. Middle panels: reconstruction using the Sech-squared profiler for night-time conditions and the Exponential profiler for day-time. Bottom panels: ionosonde and GPS-TEC measurements used as inputs to the reconstructions. 
During this period, the solar activity was relatively high $\left(176<F_{10.7}<185\right)$ and geomagnetic activity conditions quiet $(A p<12)$. Reconstructed electron profiles were ready for display well before the planned 15 min time delay limit. The model thus proved to be capable of producing density profiles every 15 min using new observations, which is a sufficiently good rate for most of the envisaged applications, including storm investigations. Post-processed graphics of the reconstructed vertical electron density, together with the used input parameters, can be seen in fig. 3.5. The effect of using the exponential profiler for day-time reconstructions (07:00-19:00 LT) is clearly seen in the middle panels. The growing availability of near-real-time GPS-TEC and ionosonde measurements and the demonstrated ability to run the profiler in near-real-time gives the model much potential. Possible applications include the testing and development of ionosphere-plasmasphere models, optimisation of HF radio systems operation, and the investigation of ionospheric storms and other space-weather studies.

\subsection{DEVELOPMENTS IN TOOLS AND METHODS}

The bulk of the work reported in this paper is concerned with developing and improving the techniques and methods that any operational nowcasting or forecasting system relies on. Two broad categories can be identified:

Updating models with prompt data - Most models of the ionosphere are correct only in an average sense since they are designed typically to describe the median behaviour of some parameter. In the era before the wide availability of global and space-based prompt data this was the only practicable approach to describing the ionospheric system. With the availability of such data this is now changing, which makes it imperative that effective methods be developed for combining the models with the new wealth of prompt data.

Modelling the ionospheric system - In tandem with assimilating prompt data into models, there has also been significant research into new modelling and observation of the ionospheric system. The work reported here explores some of the possibilities either for exploiting new data sources or using existing data in novel ways.

\subsubsection{Updating models with prompt data}

As indicated above, the availability of prompt ionospheric data now makes it realistic to seek to combine existing ionospheric models with prompt observations. Prompt data are almost invariably from a relatively small number of locations so alone they cannot always give a good regional, let alone global, picture of the ionosphere. Regional and global models, whether empirical or physicsbased, necessarily abstract away from day-to-day or hour-to-hour variability. By combining models and prompt data one would hope to get a coherent regional or global picture that is consistent with the most recent available data. Such a combination could form the basis of a nowcasting service, providing users with an accurate representation of current conditions updating in near-real-time.

Work during the present COST Action has principally focused on two areas: updating models of the standard $f_{o} F 2$ parameter, and updating models of electron density profiles.

\subsubsection{Critical frequency $f o F 2$}

\subsection{SIRMUP}

A number of ionospheric models have been developed specifically to describe the ionosphere of the European area. One of these is the Simplified Ionospheric Regional Model (SIRM) (Zolesi et al., 
1996), a regional model of the standard vertical incidence monthly median ionospheric characteristics, and work has been carried out to explore how to adapt this model with real-time data (Zolesi et al., 2004). This model is parameterised by the 12-month running mean of the International Sunspot Number, $R_{12}$, and the approach taken was to use real-time observations to adapt this driving parameter of the model to produce SIRMUP, the SIRM UPdating model.

The SIRMUP method is based on the idea that real-time values of $f \circ F 2$ at a location can be determined from the SIRM model using an effective sunspot number, $R_{\text {eff }}$, instead of the 12-month smoothed sunspot number, $R_{12}$. The method of determining $R_{\text {eff }}$ was introduced by Houminer (Houminer et al., 1993). In this approach, values of the ionospheric characteristics from an initial run of the model at a set of reference points are combined with real-time measurements at those locations. For this study, these locations were Athens, Rome, Juliusruh and Chilton, there being modern digisondes (UMLCAR Digital Portable Sounders) at each of these stations capable of providing prompt auto-scaled data. For the set of stations, indexed by $i=1, \ldots, N$ and for an arbitrary sunspot number, $R$, the mean squared error quantity

$$
\Delta(R)=\frac{1}{N} \sum_{i=1}^{N}\left|f o F 2{ }_{M}(R, i)-f o F 2 o(i)\right|
$$

is calculated, where $f o F 2_{M}(R, i)$ is the modelled $f_{o F} 2$ value at station $i$ for sunspot number $R$, and $f o F 2_{O}(i)$ is the corresponding observed value for station $i$. The 'effective' sunspot number, $R_{\mathrm{eff}}$, is then taken to be that value of $R$ that minimises $\Delta(R)$ and is thus a compromise figure chosen so that the model agrees well with observations across the full set of reference points.

To assess the qualitative improvements achieved with this method of updating, observations of foF 2 were compared with the SIRMUP predictions and the original SIRM predictions for a number of test locations (Moscow, San Vito, Sofia and Ebro) different from the reference stations used to update the model. The relative errors $e 1$ and $e 2$ in the SIRMUP and SIRM predicted values were calculated, defined by

$$
\begin{gathered}
e 1=\frac{\left|f o F 2_{\mathrm{OBS}}-f o F 2_{\mathrm{SIRM}}\right|}{f o F 2_{\mathrm{OBS}}} \\
e 2=\frac{\left|f o F 2_{\mathrm{OBS}}-f o F 2_{\mathrm{SIRMUP}}\right|}{f o F 2_{\mathrm{OBS}}}
\end{gathered}
$$

as by Houminer et al. (1993). The method of real-time updating can be regarded as successful when the criterion $(e 1-e 2)>0$ is true. Overall, the study showed that the SIRMUP predictions are much improved compared with those of SIRM, especially during large-scale ionospheric disturbances, as well as during quiet conditions, while there was a marginal improvement during localized ionospheric disturbances.

It should also be noted that the difference $\left(R_{\text {eff }}-R_{12}\right)$ can be considered as a regional index of the ionospheric activity for the European region. The distribution of the $\left(R_{\mathrm{eff}}-R_{12}\right)$ parameter for the cases when $(e 1-e 2)$ is positive and negative is presented in fig. 3.6a. This demonstrates the superiority of SIRMUP over SIRM since for all values of $\left(R_{\mathrm{eff}}-R_{12}\right)$ the number of cases for which $(e 1-e 2)>0$ always exceeds the number of cases for which $(e 1-e 2)<0$. There is also an indication that the relative performance of the two models depends on the level of ionospheric disturbance, as characterised by $\left(R_{\text {eff }}-R_{12}\right)$. This point is further exemplified by fig. $3.6 \mathrm{~b}$, which shows the distribution of $\left(R_{\mathrm{eff}}-R_{12}\right)$ only for those cases for which $|e 1-e 2|$ exceeds 0.05 . This eliminates those cases for which the performance of the two models differed only marginally. This figure reveals 

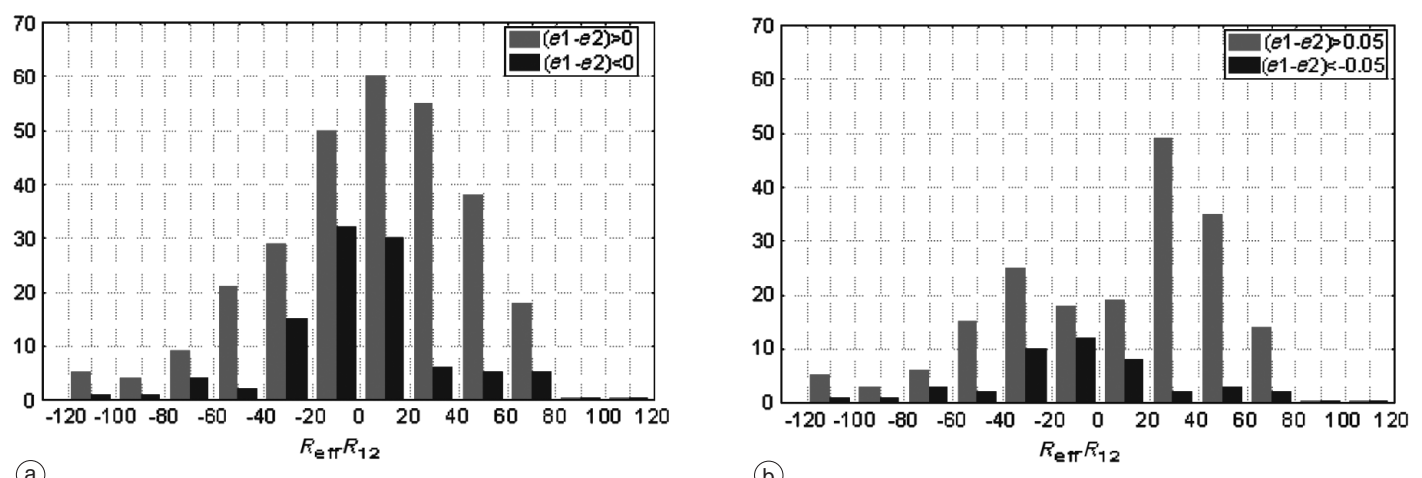

(a)

Fig. 3.6a,b. Distribution of $\left(R_{\mathrm{eff}}-R_{12}\right)$, for the cases when SIRMUP performs better than SIRM (pale grey) and when SIRMUP performs worse than SIRM (dark grey): a) for all cases; b) only for those cases where the difference in the relative errors $e 1$ and $e 2$ exceed 0.05 .
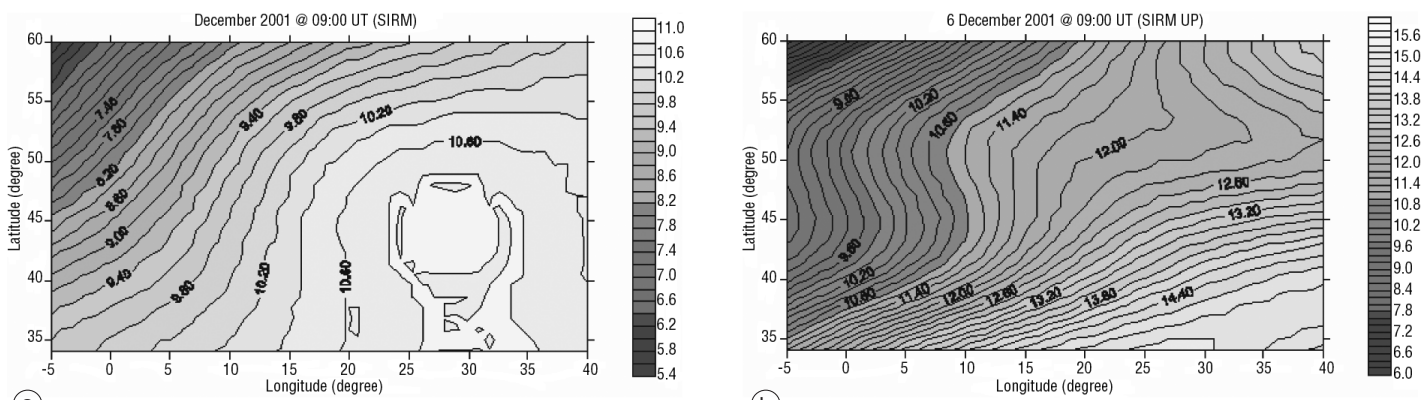

(a)

Fig. 3.7a,b. The European $f o F 2$ maps for 6 December 1991, 09:00 UT, produced by the SIRM and SIRMUP models: a) SIRM output; b) SIRMUP output.

that the performance of SIRMUP most strongly improves over SIRM for cases where the ionospheric activity is moderate to intense. In cases of very intense activity, SIRMUP performance is still improved but the number of cases is too small to be statistically significant.

In general the study clearly demonstrated that the procedure of updating SIRM with automatically scaled ionospheric parameters from four European digisondes has the potential to be used in real-time for nowcasting the standard ionospheric characteristics over Europe. The final output from the method is a map of $f o F 2$ covering the European area from $5^{\circ} \mathrm{W}$ to $40^{\circ} \mathrm{E}$ in longitude and $34^{\circ} \mathrm{N}$ to $60^{\circ} \mathrm{N}$ in latitude. Figure $3.7 \mathrm{a}, \mathrm{b}$ shows examples of the maps of foF 2 produced by SIRM (fig. 3.7a) and SIRMUP (fig. 3.7b) for 6 December 2001 at 09:00 UT when the relative performance of SIRMUP, measured by the $(e 1-e 2)>0$ criterion, was particularly good. The foF 2 values 
in the SIRMUP generated map are greater than those produced by SIRM, and the topology of the ionosphere is much better determined, especially in the southeast region where SIRMUP describes well a latitudinal dependence of $f_{o} F 2$.

\subsection{ISWILM}

An alternative approach to updating models of critical frequencies is to modify the model outputs directly in a systematic way determined by the real-time observations, rather than doing so indirectly by adjusting the model parameters. This direct approach was taken by another study using a European regional ionospheric model, the Space Weighted Ionospheric Local Model (SWILM) (Franceschi and Perrone, 1999; De Franceschi et al., 2000).

The SWILM covers the area from $35^{\circ} \mathrm{N}$ to $70^{\circ} \mathrm{N}$ in latitude and $5^{\circ} \mathrm{W}$ to $40^{\circ} \mathrm{E}$ in longitude, and provides monthly medians of $f \circ F 2$ at a given epoch (month and time of day) on a grid with a step of $5^{\circ}$ in longitude and $2.5^{\circ}$ in latitude. Work by Pietrella and Perrone has investigated modifying the output of the SWILM using prompt foF2 data, resulting in the 'Instantaneous' SWILM, ISWILM. The method is to take observations from a set of reference stations, and determine the difference between the model SWILM value for that station and the observed value. This set of differences is then used to define a correction for any arbitrary point in the model area in a spaceweighted manner.

For a reference station $j$ at some time $t$, the difference function

$$
\Delta F(j, t)=f o F 2(j, t)_{\text {med }}-f o F 2(j, t)_{\text {obs }}
$$

is computed where $f o F 2(j, t)_{\text {med }}$ is the SWILM modelled median value of $f o F 2$ and $f o F 2(j, t)_{\text {obs }}$ is the observed $f o F 2$ value. For an arbitrary point $P$ on the model grid a correction is derived from the $\Delta F(j, t)$ values from the reference stations.

First, the model area is divided into latitude sectors each $\Delta S$ wide, in this case $5^{\circ}$, because an assumption of the SWILM model is that the ionosphere has essentially the same behaviour over $5^{\circ}$ of latitude. For an arbitrary point $P$ in the model area, these sectors are centred on $P$ and consist of those areas whose latitudes fall within the ranges

$$
R_{P, K}=[\operatorname{Lat}(P)-K \Delta S, \operatorname{Lat}(P)+K \Delta S] \quad K=1 \ldots M .
$$

For each of the $M$ latitude sectors, the mean of the differences for all of the reference stations within that sector is computed. This quantity, $D_{K}$

$$
D_{K}(P, t)=\sum_{j: \text { Lat }}(j) \in R_{P, k} \Delta F(j, t) \quad K=1 \ldots M
$$

provides a single representative measure of the differences between the SWILM model outputs and observations for that sector. Finally, the $D_{K}$ values for all sectors are combined to give a correction factor $\Delta f(P, t)$ for the point $P$ at time $t$, using an attenuation factor $\Lambda$. This attenuation factor is used to weight more strongly the $D_{K}$ values for sectors that are closer to the point in question

$$
\Delta f(P, t)=(1-\Lambda) \sum_{K=1}^{M} \Lambda^{K-1} D_{K}(P, t) \quad \Lambda \in[0,1] .
$$


The ISWILM now-casting algorithm then defines the foF2 value for the point $P$ at time $t$ as

$$
f o F 2(P, t)_{\text {pred }}=f o F 2(P, t)_{\text {med }}+\Delta f(P, t) \quad K=1 \ldots M
$$

For this exploratory study the reference stations were Rome, Chilton, Lycksele and Loparskaya (or Sodankyla). A set of test stations was also used to examine the accuracy of the resulting model; the test stations were Tortosa, Juliusruh, Uppsala and Kiruna. The geographic locations of all the stations are given in table 3.I, where those with a ' $T$ ' or ' $R$ ' in the ISWILM column were used in this study. Given that the SWILM model on which the ISWILM model is based already delivers median ionospheric characteristics, a good test of the updating strategy can only be obtained if its performance is studied under disturbed conditions. To this end, several such intervals were selected as test cases.

Note that the correction function $\Delta f(P, t)$ is a function of the attenuation factor $\Lambda$ (eq. (3.7)). For the selected test intervals a global daily error function was calculated for each station as the root mean squared error of prediction, with $\Lambda$ varying between 0.1 and 0.9 in steps of 0.1 . It was

Table 3.I. Ionosonde stations. The ISWILM and IRI- 2000 columns indicate the use made of data from the stations in the studies described in Sections 3.4.1.1.2 and 3.4.1.2.1 respectively.

\begin{tabular}{lccccc}
\hline \hline Station name & Code & Latitude & Longitude & ISWILM & IRI-2000 \\
\hline Athens & AT138 & $38.0 \mathrm{~N}$ & $\mathrm{E}$ & & \\
Chilton & RL052 & $51.5 \mathrm{~N}$ & $\mathrm{E}$ & $\mathrm{R}$ & $\mathrm{X}$ \\
El Arenosillo & EA036 & $37.1 \mathrm{~N}$ & $\mathrm{E}$ & & $\mathrm{X}$ \\
Juliusruh & JR055 & $54.6 \mathrm{~N}$ & $\mathrm{E}$ & $\mathrm{T}$ & $\mathrm{X}$ \\
Kiruna & KI167 & $67.8 \mathrm{~N}$ & $\mathrm{E}$ & $\mathrm{T}$ & \\
Loparskaya & LS168 & $69.0 \mathrm{~N}$ & $\mathrm{E}$ & $\mathrm{R}$ & \\
Lycksele & LY164 & $64.6 \mathrm{~N}$ & $\mathrm{E}$ & $\mathrm{R}$ & $\mathrm{X}$ \\
Pruhonice & PQ052 & $50.0 \mathrm{~N}$ & $\mathrm{E}$ & & $\mathrm{X}$ \\
Rome & RO041 & $41.9 \mathrm{~N}$ & $\mathrm{E}$ & $\mathrm{R}$ & $\mathrm{X}$ \\
Sodankyla & SO166 & $67.4 \mathrm{~N}$ & $\mathrm{E}$ & $\mathrm{R}$ & $\mathrm{T}$ \\
Tortosa/Ebre/Ebro & EB040 & $40.8 \mathrm{~N}$ & $\mathrm{E}$ & $\mathrm{T}$ & $\mathrm{X}$ \\
Uppsala & UP158 & $59.8 \mathrm{~N}$ & $\mathrm{E}$ & $\mathrm{T}$ & \\
Warsaw & MZ152 & $52.1 \mathrm{~N}$ & $\mathrm{E}$ & & \\
\hline
\end{tabular}
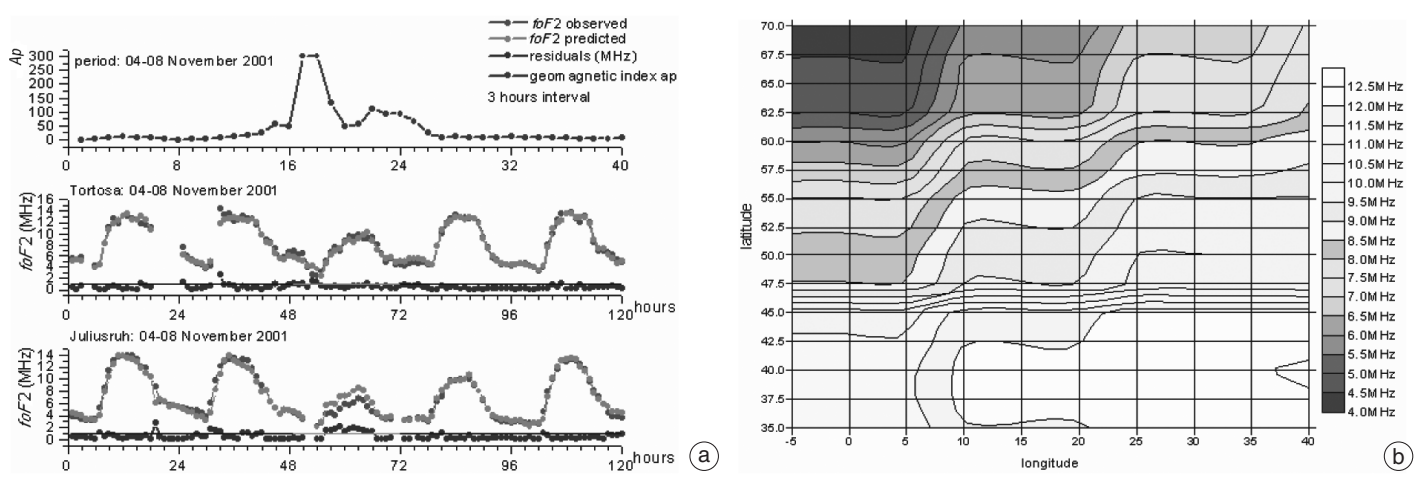

Fig. 3.8a,b. Outputs from the ISWILM model: a) the predictions for Tortosa and Juliusruh for 4-8 November 2001; b) instantaneous mapping of $f o F 2$ for 7 November 2001. 
found that the error was minimised for Tortosa with $\Lambda=0.3$, and $\Lambda=0.1$ for the other testing stations of Juliusruh, Kiruna and Uppsala. The reason for the difference seems clear - the greater variability of the ionosphere at higher latitudes implies that the error contributions from remote reference stations should be attenuated more severely, hence the lower attenuation factor.

Figure 3.8a illustrates the performance of the ISWILM model during the period of 4-8 November 2001. This was a particularly disturbed period with a maximum $A p$ value of 300 , the most intense solar proton event of that solar cycle at the time (reaching a PFU of 31700 for particles with energies $>10 \mathrm{MeV}$ ), an $X 1$ flare and a halo CME. The upper panel shows the geomagnetic $A p$ index, with the middle and lower panels showing observed and predicted $f o F 2$ values together with the difference between them for Tortosa and Juliusruh, respectively. The effect of the storm on the $f o F 2$ values is clear, and the model can be seen to be doing moderately well in reproducing the deviations from the median behaviour, particularly for Tortosa where the residuals are predominantly below $1 \mathrm{MHz}$, even during the most disturbed period. Figure 3.8a shows the results for a single station. By generalising the findings on the most appropriate attenuation factor to use to cover the entire model area, full-area maps of foF 2 can be produced. Figure 3.8b shows an example taken from the same interval as fig. 3.8a. This was produced with $\Lambda=0.3$ for latitudes in the range $\left[35^{\circ} \mathrm{N}, 45^{\circ} \mathrm{N}\right]$ and $\Lambda=0.1$ for higher latitudes in the range $\left[47.5^{\circ} \mathrm{N}, 70^{\circ} \mathrm{N}\right]$.

The map illustrates the standard longitude dependence inherited from the underlying SWILM model, superimposed on which there is a marked foF 2 decrease in the north-west. There clearly are some artefacts of the model present, for example, the steep gradient between $45^{\circ} \mathrm{N}$ and $47.5^{\circ} \mathrm{N}$ where the attenuation factor changes. It is to be expected that by varying $\Lambda$ more smoothly this effect could be eliminated. In summary, this ISWILM approach to model adaptation shows some promise in providing a method for assimilating prompt data into a model to produce a now-casting product.

\subsubsection{Electron density profiles}

\subsection{Updating IRI-2000}

The International Reference Ionosphere (IRI) (Bilitza, 2001) is one of the most widely used empirical models. Among other things, it describes the median values of electron density as a function of height for a given location, time and sunspot number. The IRI model is being refined following the annual IRI workshops and currently contains a model for foF2 storms (Araujo-Pradere et al., 2002; Bilitza, 2003). Further improvements could be made if a satisfactory method could be found for real-time updating of the ionospheric electron density profile, $N(h)$, over Europe, based on the IRI-2000 and including real-time measurements from ionosondes. Burešová et al. (2004) examined a method for combining modelled IRI-2000 $N(h)$ profiles produced using IRIweb (http://nssdc.gsfc.nasa.gov/ space/model/models/iri.html) with real-time $N(h)$ profiles from European ionosondes obtained via the COST 271 Space Weather Database (http://www.wdc.rl.ac.uk/cgibin/di-gisondes/costdatabase.pl).

An initial comparison of the measured and IRI-generated $N(h)$ profiles was done for two European ionospheric stations: Pruhonice and Ebro. Some of the results obtained for the period of 14-21 February 1998 are shown in fig. 3.9. In this period the first three days were geomagnetically quiet, followed by a storm on 18 February and then a long recovery phase. At Pruhonice it can be seen that: i) there is a good agreement between the IRI model (red line) and $N m F 2$ measured data (black line) for the whole period; ii) in general, there is no agreement between the IRI model and measured values of the electron density at F1-region heights. This is particularly true during the main phase of the geomagnetic storm and at a height of $180-190 \mathrm{~km}$ in the F1-region. The same general picture holds true for the similar comparison made for Ebro, shown in the right-hand panel of the figure. A number of explorations of the effect of combining model and observational data were carried out, with a particular focus on the peak $F 2$-layer electron density, $N m F 2$, and the electron density at a rep- 

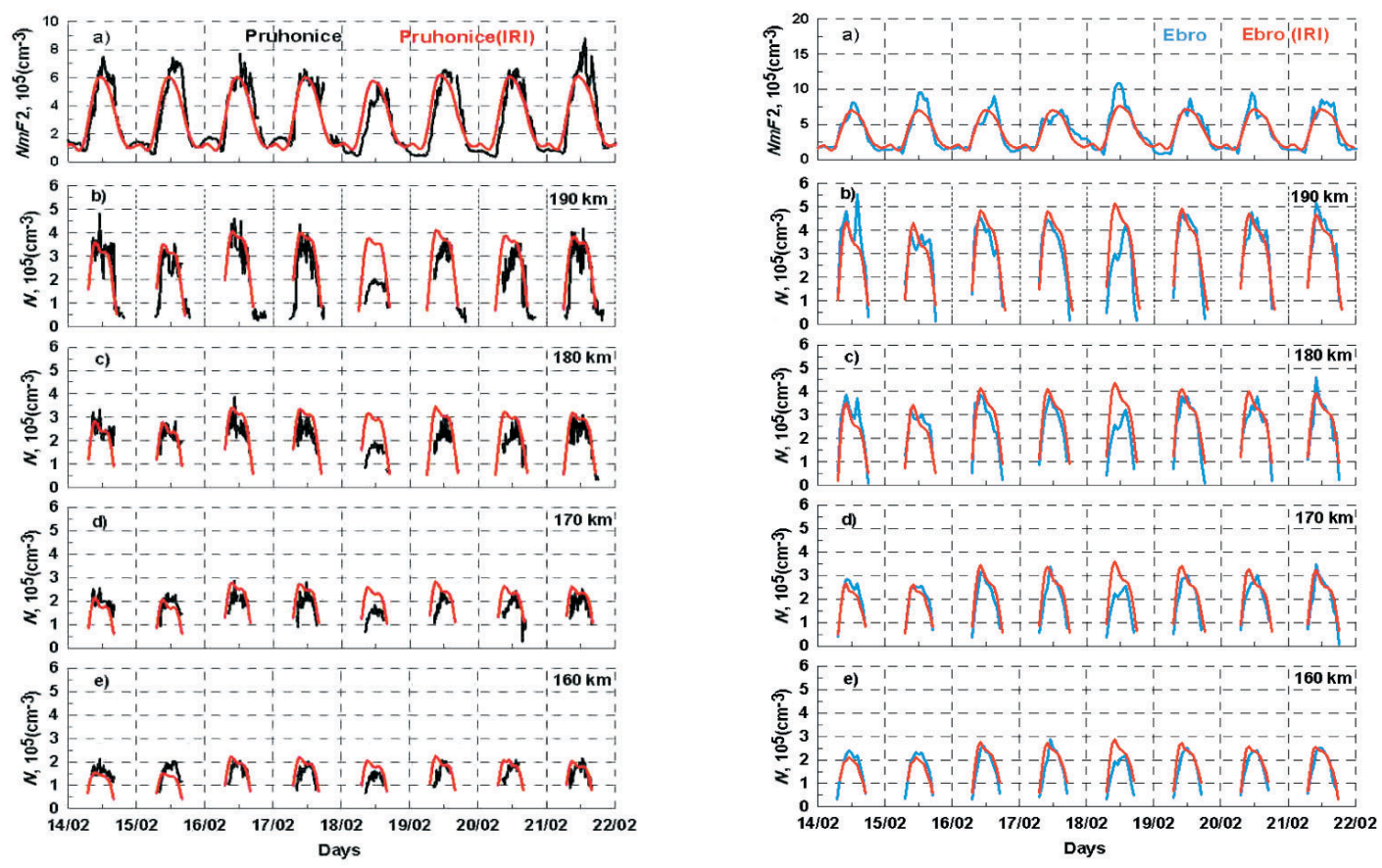

Fig. 3.9. Hourly $N m F 2$ values and electron density values at specific heights at Pruhonice (left panel) and at Ebro (right panel) stations during the period 14-21 February 1998. The output of the IRI model is shown in red, and observational data is shown in black (Pruhonice) or blue (Ebro).

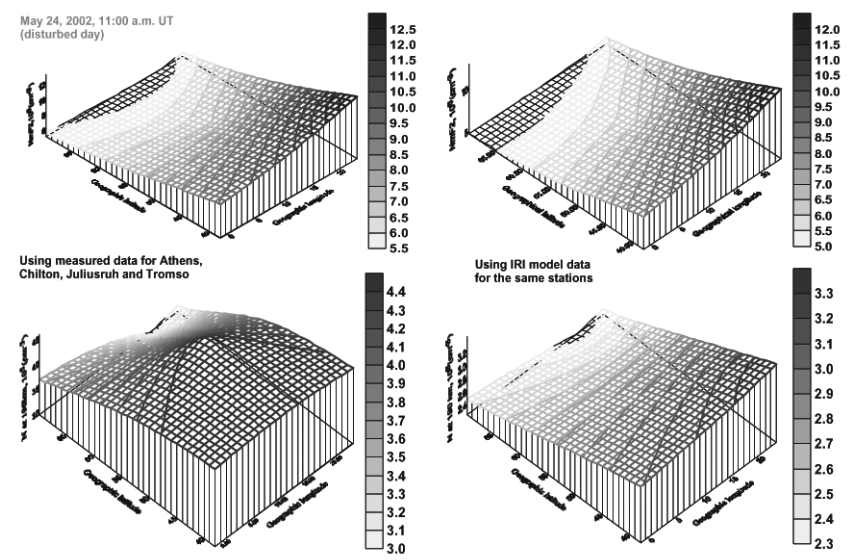

Fig. 3.10a. Plots of $h m F 2$ and electron density and $190 \mathrm{~km}$ across the European area, produced by combinations of the IRI-2000 model and observations. The top pair of graphs shows NmF2 and the bottom pair show the $190 \mathrm{~km}$ electron density derived from values at Athens, Chilton, Juliusruh and Troms $\varnothing$; the left-hand pair uses observed data and the right-hand pair uses IRI-2000 data for the same four locations. 

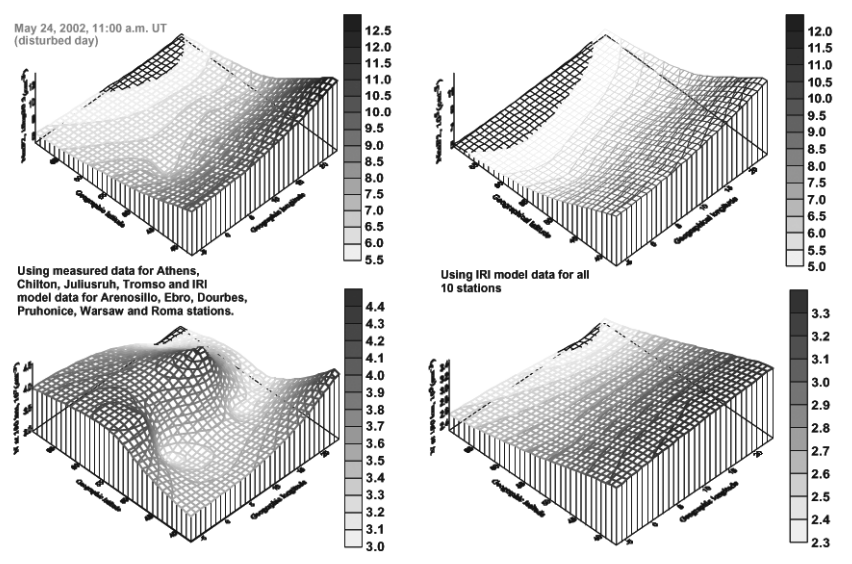

Fig. 3.10b. Plots of $h m F 2$ and electron density and $190 \mathrm{~km}$ across the European area, produced by combinations of the IRI-2000 model and observations. The top pair of graphs shows $N m F 2$ and the bottom pair show the $190 \mathrm{~km}$ electron density derived from values at Athens, Chilton, Juliusruh, Troms $\varnothing$, El Arenosillo, Dourbes, Ebro, Pruhonice, Roma and Warsaw; the left-hand pair uses observed data for the first four stations and IRI data for the other six; the right-hand pair uses IRI-2000 data for all ten locations.

resentative $F$ 1-layer height of $190 \mathrm{~km}$. Figure 3.10a,b illustrates the findings, showing plots of $\mathrm{NmF2}$ and the $190 \mathrm{~km}$ electron density for 11:00 UT on 24 May 2003 across the European area. This was a ionospherically disturbed day, with a minimum value of Dst of -108 nT during the late evening of the previous day. Both plots follow the same pattern, with the top two panels plotting $N m F 2$ and the bottom two the $190 \mathrm{~km}$ electron density, and the surfaces being produced by interpolation from a number of data points. Figure 3.10a shows the result of using measured data from the stations at Athens, Chilton, Juliusruh and Troms $\varnothing$ in the left-hand column, and in the right-hand column the equivalent plots for IRI-generated data for the same locations. It can be seen that the IRI underestimates the electron density at $190 \mathrm{~km}$ quite substantially, although it performs better at modelling $N m F 2$. Figure 3.10 b shows similar plots but using, in the left-hand column, a combination of the same measured data as in fig. 3.10a and IRI data for several other locations where ionospheric sounders are present. This figure makes clear how different the observed and IRI-modelled values are, with a large trough apparent in the electron density where no observational data were available. This gives a graphic indication of how combining data and model outputs needs to be approached with caution.

\subsection{Updating the NeQuITUR model}

Another study (Stanisławska et al., 2004) looked at both the IRI-2000 (Bilitza, 2003 and see ftp://nssdcftp.gsfc.nasa.gov/models/ionospheric/iri/) and the NeQuITUR models (Leitinger, 1997), the latter having been developed as part of the earlier COST 251 Action. Careful attention was paid to the method used for constructing maps from spatially distributed measured data, since virtually every type of mapping is imperfect and can generate significant errors, especially in areas only sparsely covered by data. Again, an output of the COST 251 Action was taken as a starting point, namely the mapping scheme PLES (Stanislawska et al., 2001) which was then developed further.

Two interpolation techniques were investigated: 
1) A modification of the geostatic Kriging technique that consists of interpolating the deviations of measurements from the background model.

2) A new fitting technique specifically developed for this application which weights the contribution of measurements using the probability distribution function.

In both cases, the interpolation was done using the deviation of the observations from the chosen background model.

Kriging is a statistical description method based on the characteristic variability of a parameter, as captured by a variogram. The value of the parameter at a point between locations where it has been measured is determined by interpolation, using weights dependent on the distance to those points and the degree of correlation of the parameter in the neighbourhood. The precision of this directional correlation, as captured by the variogram, depends on the size of the data sample and its spatial distribution. If the variogram is anisotropic, as is the case with the ionosphere, a scaling factor, $S F$, is applied before the interpolation procedure is completed. In this case, $S F$ is the ratio of the length of the E-W and N-S axes of the spatial correlation ellipse. In general, $S F$ is not the same for all map areas and for all levels of geomagnetic activity, but for this study the simplifying assumption was made to use a single averaged $S F$ value throughout the studied area and the selected period for each parameter. For $f o F 2$ the value of the axes ratio of the correlation ellipse in mid-latitudes was found to be roughly two, while for $f o F 1$ and $f o E$ it was approximately one.

The novel fitting method developed for this study used an anisotropic weighting for determining the contribution of neighbouring measured values to the interpolated value at an arbitrary point. Specifically, the weight function $W$ has the form

$$
W=\exp -\left((d x / R x)^{2}+(d y / R y)^{2}\right)
$$

where $d x$ and $d y$ are the longitudinal and latitudinal distances from an observation to the point for interpolation, and $R x$ and $R y$ are the correlation radii in the longitudinal and latitudinal directions.

Both interpolation techniques were tested on the IRI-2000 and NeQuITUR models with the measured data taken from the stations marked in the IRI-2000 column of table 3.I. Combinations of model and interpolation method were assessed using a leave-one-out approach, where the error of a set of predictions is assessed at one location using observations from all the other stations as inputs. Predictions were made over a range of heights, dates and times including both quiet and disturbed intervals. A summary of the results can be seen in table 3.II. A single example of how the various methods and background models handle this is shown in fig. 3.11. This figure presents the ionospheric profile at Pruhonice at 12 UT on 15 July 2000, as obtained by ionogram inversion and as produced by the IRI model, the NeQuITUR model and both the Kriging and novel fitting methods of adapting the NeQuITUR model to data. The usual inversion procedure cannot be relied upon at low altitudes, which is why the graph does not go below $100 \mathrm{~km}$, but in the region shown the most accurate reconstruction of the true profile was clearly obtained by using Kriging to adapt the NeQuITUR model.

Table 3.II. Results of IRI-2000 and NeQuITUR height profile adaptation, broken down by station and year. Against each prediction method is shown the average percentage deviation for the specified station or period.

\begin{tabular}{lcccccccccc}
\hline \hline Method & Total & JR055 & MZ152 & RL052 & PQ052 & RO041 & EB040 & EA036 & 1998 & 2000 \\
\hline NeQuITUR & 32.8 & 37.6 & 36.6 & 26.7 & 30.3 & 37.5 & 31.1 & 29.2 & 34.0 & 31.9 \\
Kriging (NeQuITUR) & 27.1 & 23.8 & 30.6 & 22.1 & 27.9 & 24.8 & 20.9 & 37.3 & 31.9 & 23.1 \\
Fitting (NeQuITUR) & 27.1 & 27.0 & 26.3 & 23.6 & 21.8 & 33.7 & 29.1 & 27.7 & 30.4 & 24.3 \\
IRI-2000 & 32.6 & 29.2 & 41.1 & 27.1 & 32.8 & 30.2 & 29.9 & 36.4 & 38.2 & 27.2 \\
Kriging (IRI-2000) & 34.7 & 29.6 & 48.7 & 36.5 & 46.6 & 25.1 & 24.1 & 37.1 & 38.9 & 28.0 \\
Fitting (IRI-2000) & 29.6 & 29.2 & 35.0 & 25.8 & 27.4 & 28.3 & 26.5 & 33.3 & 32.4 & 24.0 \\
Number of data & 23760 & 3683 & 3408 & 2349 & 3564 & 2990 & 3846 & 3920 & 10707 & 13053 \\
\hline
\end{tabular}




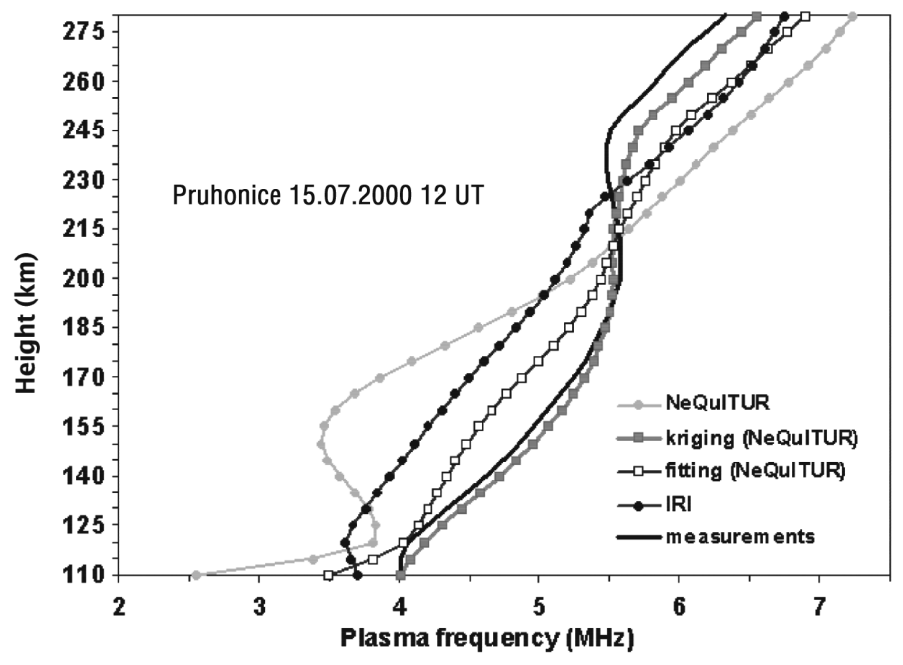

Fig. 3.11. Example of plasma frequency (electron density) height profiles at Pruhonice for 12 UT on 15 July 2000. The plot shows the profile inverted from the ionogram (solid line), and the profiles reconstructed by the IRI model, the NeQuITUR model, and the kriging and fitting adaptations of the NeQuITUR model.

From this preliminary study it is clear that both interpolation procedures are suitable for constructing electron concentration images, whether retrospectively or in real-time. The errors are larger than have customarily been found for studies that looked at a single parameter such as foF 2 ; this is unsurprising since reconstructing the full three-dimensional electron density profile is a significantly more challenging problem, and more work is being done to improve the accuracy of the approach.

\subsubsection{The ionosphere-magnetosphere system}

\subsubsection{Geomagnetic disturbances}

Geomagnetic disturbances are used in much of the work described earlier in this paper to identify periods of interest that are challenging for models to handle. Kutiev and other authors have developed an analogue model of the $K p$ index as a function of the Interplanetary Magnetic Field IMF$B z$ component. The model uses a modified $B z$ function (denoted as $B z m$ ), which exhibits a delayed reaction to $B z$ changes. The function $B z m$ was defined using the analogy with a damping RC-circuit output voltage and is characterised by two time constants, one for rising and one for decreasing parts of $B z$. The model expression for $K p$ depends on $B z m$, solar wind velocity $V$ and dynamic pressure $P$ (where $P$ is calculated as $P=1.67310^{-6} n V^{2}$ and $n$ is the ion density)

$$
K p=-2.3+0.64 B z m+0.31 P+0.007 V-0.24 B z m^{2}-0.01 P^{2}
$$

The coefficients are obtained by fitting the expression in eq. (3.10) to the full set of ACE data for the period 1998-2000. Figure 3.12a shows a comparison between observed and modelled $K p$ dur- 

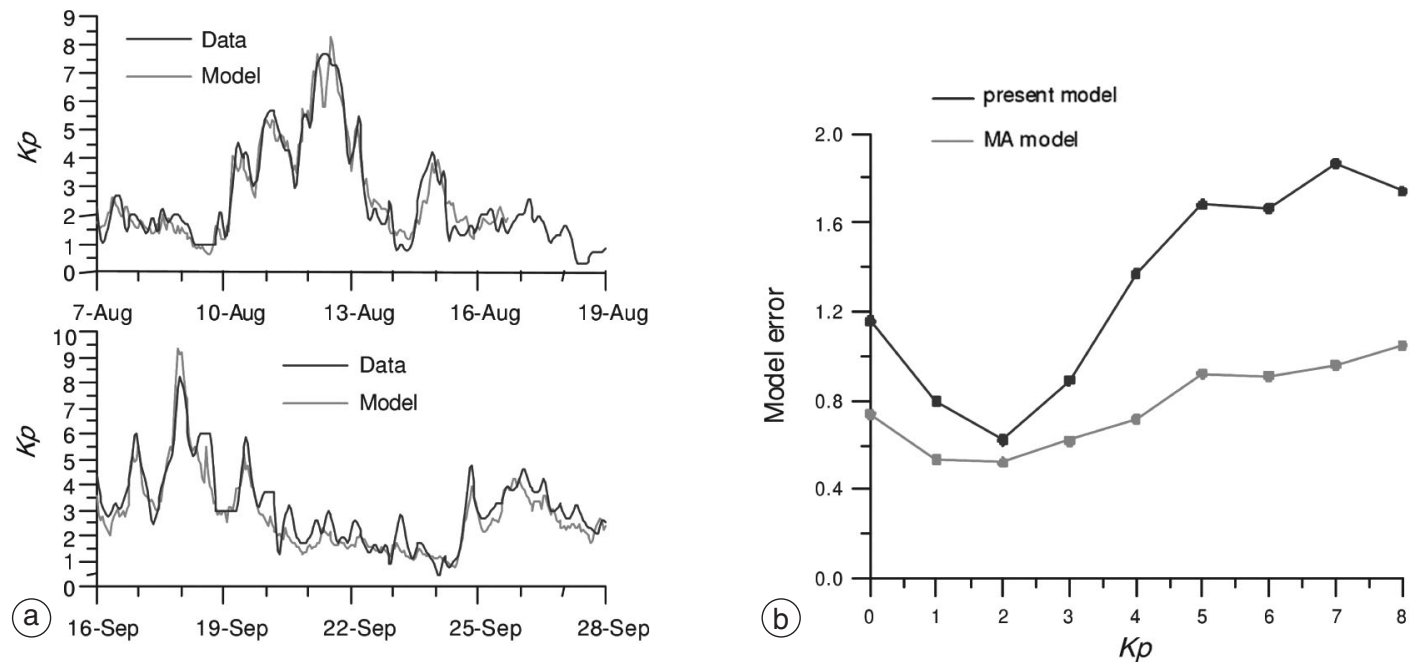

Fig. 3.12a,b. Performance of the Kutiev model of $K p$ : plot (a) actual and modelled $K p$ values for 7-19 August 200 and 16-28 September 2000; plot (b) the RMS error of the Kp and the Muhtarov-Andonov model, calculated using ACE data covering 1998-2000 and binned by Kp units.

ing 1-19 August and 16-28 September 2000, where the dark line shows the observed $K p$ and the pale line presents the model prediction. The agreement between the model and observations in these samples is acceptable. Although the model overestimates the peak values of $K p$ during its sharp increase on 12 August and 18 September 2000, overall the agreement between the model and observations in these samples is acceptable with both the increasing and decreasing parts of $K p$ changes being well reproduced. An estimate of the overall model error is given by the average root mean square deviation between the observed and model $K p$ estimated over the whole database, and is $0.63 \mathrm{Kp}$ units. Figure $3.12 \mathrm{~b}$ shows the model error calculated separately in unit-wide bins of $K p$ magnitude. The minimum error of 0.52 is found around $K p=2$, which coincides with the most likely $K p$ value. At $K p=8$, the error increases to 1.04 . For comparison, the error of the Muhtarov-Andonov model is also shown, which has an average model error overall $K p$ values of 0.96 . Work on the model is on-going with further improvements having been made recently reducing the model error to 0.1 at $K p=2$ and 0.9 at $K p=8$.

\subsubsection{Features of the ionosphere}

\subsection{Global ionospheric response to geomagnetic activity}

Kutiev and Muhtarov have also developed an empirical model describing the distribution of the relative deviation of $f o F 2$ from its median on a global scale (Kutiev and Muhtarov, 2003). At any given time this relative deviation, denoted by $\Phi$, is represented by diurnal and semidiurnal waves standing along the local time. The standing waves are expressed by five parameters: daily mean (average offset), diurnal and semidiurnal amplitudes and phases. The model expression is scaled by a modified function of $K p$, which reflects the delayed reaction of $f o F 2$ to $K p$ changes. The model parameters are determined by fitting the model expression separately to the data from each of 55 ionosonde 


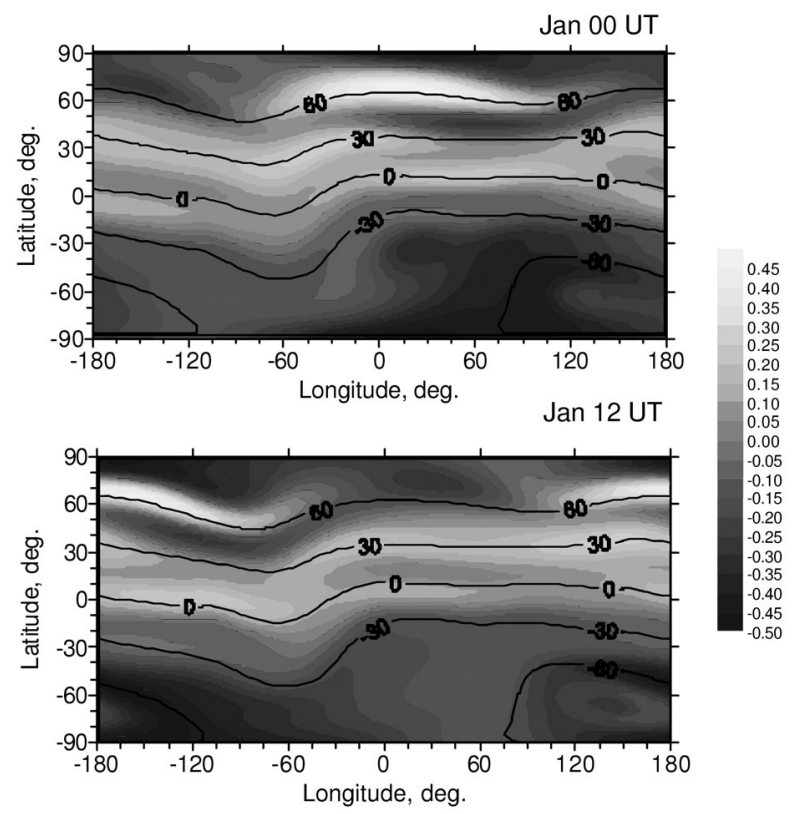

Fig. 3.13. The distribution of the relative deviation $\Phi$ of $f o F 2$ from its median value shown for January at 00 UT (upper panel) and 12 UT (lower panel).

stations. Their distribution across geomagnetic latitudes is obtained in three longitude sectors: NorthSouth America, Europe-Africa and East Asia-Australia. In order to produce a global distribution of each of the model parameters, the respective latitudinal profiles from the three sectors were averaged and approximated by analytical expressions.

The global distribution of $\Phi$ is shown in fig. 3.13 for January 00 UT (top panel) and 12 UT (bottom panel). The solid lines mark parallels at $0^{\circ}, 30^{\circ}$ and $60^{\circ}$ geomagnetic latitude. The distribution of $\Phi$ at 12 UT is that of $00 \mathrm{UT}$, shifted by $180^{\circ}$ along in geographic longitude. In the summer hemisphere $\Phi$ is generally negative, with the maximum diurnal amplitude (the phase) centred at $60^{\circ} \mathrm{E}$ longitude (16 h local time). In the equatorial zone, $\Phi$ is always positive with small diurnal variations, with the phase placed in the morning hours. At northern mid-latitudes $\left(40^{\circ}-50^{\circ}\right)$, the maximum diurnal variation is in the late afternoon hours, with a clear negative $\Phi$ in the early morning sector. Above $60^{\circ}$ geomagnetic latitude a well pronounced peak of $\Phi$ is seen around midnight, reflecting the large diurnal amplitudes observed within the winter auroral oval.

\subsection{The mid-latitude trough}

Turning from global modelling to regional modelling of the ionosphere, neural networks have been applied to the description of a notable feature of the ionosphere in the European area - the midlatitude trough. The trough exhibits abrupt gradients in electron densities within relatively short horizontal distances and can also vary significantly in time. The extent and depth of the trough depends on many factors such as latitude, longitude, local time, season, solar activity and geomagnetic activity. The behaviour and influence of the trough on propagation conditions has proved difficult to mod- 
el analytically, so the approach adopted by Tulunay and co-workers was to use the flexible modelling capabilities of neural networks to capture the variability of the trough. Previous work (Tulunay et al., 2001) concentrated on the temporal variations seen in foF 2 at single locations due to the trough, and this work has been now been extended to examine spatial variations.

An artificial neural network is a system of inter-connected computational elements, the neurons, operating in parallel, arranged in patterns similar to biological neural nets and modelled after the human brain. Typically, such a network will have multiple layers of neurons; one for accepting inputs, one for providing outputs, and some number of 'hidden' layers connecting the input and output layers. The Middle East Technical University Neural Network (METU-NN) Model was used in this work, and has three layers, one input, one hidden and one output, with the network being trained using the Levenberg-Marquardt back-propagation algorithm.

It is difficult to obtain spatially representative trough data for a region from ground stations so the study used foF 2 data returned by the Russian INTERCOSMOS-19 satellite providing data coverage rich in quantity and quality (Karpachev et al., 1996). Northbound and southbound satellites passes over a region between approximately $40^{\circ} \mathrm{N}$ and $72^{\circ} \mathrm{N}$ Invariant Magnetic Latitude and $0^{\circ} \mathrm{E}$ and $95^{\circ} \mathrm{E}$ geographical longitude were used for the training and testing phases of the neural network model. The data chosen were so-called 'Night Time Quiet' (NTQ) data, between $18 \mathrm{~h}$ and $06 \mathrm{~h}$ local time and with the $K p$ index between 0 and $3+$, since the trough is most readily apparent under these conditions when the ionosphere is not disturbed by geomagnetic storms or the terminator. Details of the data used are shown in table 3.III, and the range of shapes of the trough for this dataset for different local times is illustrated by fig. 3.14.

The METU-NN was trained using the 1979-1980 winter data in a configuration with 22 input neurons, a hidden layer with 4 neurons and an output layer with a single neuron to give the foF 2 value. The inputs to the network encode the magnetic activity level $(K p)$, the local time, the geographic position and invariant magnetic latitude, the geographic and invariant latitudes and $f_{o} F 2$ values of the two previous and following observations (in a spatial sense) and the first and second differences of the $f_{o F} 2$ values for northbound and southbound satellites passing over the region of interest. Examples of the output from the network on the testing dataset are shown in fig. 3.15a,b.

It is clear that the network is entirely capable of representing the trough data, a conclusion borne out by a correlation analysis for the full test dataset from the 1980-1981 winter: the absolute average error was only $0.08968 \mathrm{MHz}$ with a normalised error of 0.02335 . The RMS error was $0.14633 \mathrm{MHz}$ and the correlation coefficient between the observed and predicted datasets was 0.99464 . More work will be required before the model is suitable for operationally predictive use, since it is currently dependent on a relatively dense set of inputs, but the potential of the method has been well demonstrated.

Table 3.III. Data coverage for the training and testing of the METU-NN for trough prediction.

\begin{tabular}{lcc}
\hline \hline & Training data & Testing data \\
\hline Years & $1979-1980$ & $1980-1981$ \\
Dates & $21-28$ November, & $22-28$ November, \\
& $5-21$ December, & $1-27$ December, \\
& $20-30$ January, & $6-31$ January, \\
LT $(h)$ & $2-10$ February. & $1-10$ February. \\
$K p$ & $18-24-06$ & $18-24-06$ \\
Geographic latitude & $0-3$ & $0.6667-3.3333$ \\
Invariant latitude & $38.00 \mathrm{~N}-73.60 \mathrm{~N}$ & $40.05 \mathrm{~N}-75.20 \mathrm{~N}$ \\
Geographic longitude & $40.45 \mathrm{~N}-70.34 \mathrm{~N}$ & $41.26 \mathrm{~N}-72.62 \mathrm{~N}$ \\
Number of points & $0.00 \mathrm{E}-60.00 \mathrm{E}$ & $0.00 \mathrm{E}-95.00 \mathrm{E}$ \\
& 2965 & 2265
\end{tabular}



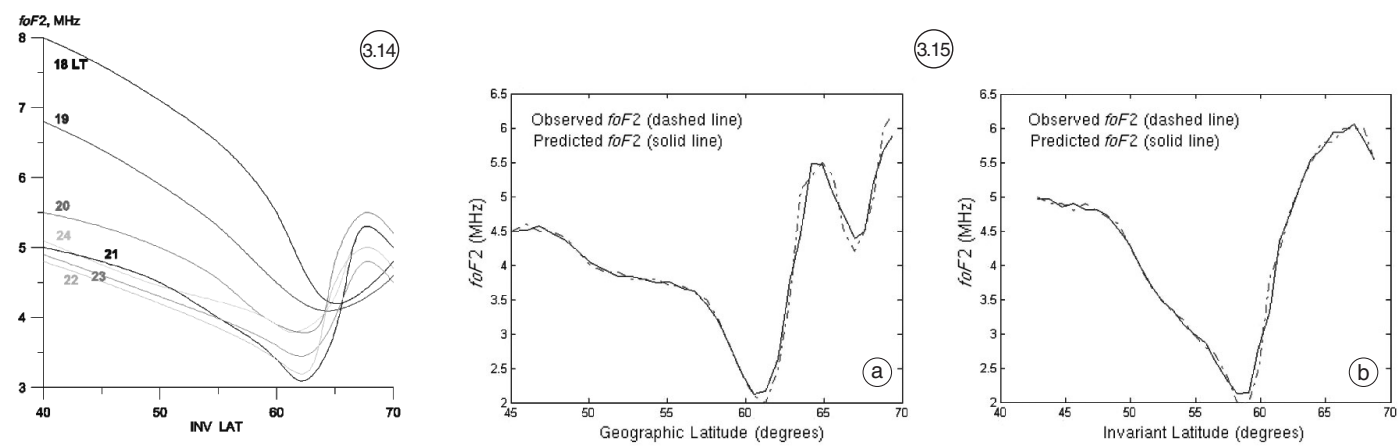

Fig. 3.14. An illustration of the range of positions and shapes of the mid-latitude trough, showing the invariant magnetic latitudinal variation of the averaged $f_{o F} 2$ values at various fixed local times, for the data in the periods listed in table 3.III.

Fig. 3.15a,b. The predicted $f o F 2$ position and shape of the mid-latitude trough, from data and as modelled by the METU-NN neural network model. a) METU-NN predicted $f o F 2$ values against geographic latitude, with longitude $55^{\circ} \mathrm{E}$, local time $02: 42$ and $K p=2$. b) METU-NN predicted $f o F 2$ values against invariant latitude, with longitude $10^{\circ} \mathrm{E}$, local time 03:00 and $K p=2$.

\subsubsection{TEC comparison and forecasting}

The effect of the earth's ionosphere on earth-space communication systems, especially during extreme space weather events is unambiguous. Radio signals travelling through the Earth's ionosphere are delayed by the integrated electron density (Total Electron Content - TEC) along the signal path between the satellite and the receiver. So TEC is a key parameter that describes the major impact of the ionized atmosphere on the propagation of radio waves, which is crucial for terrestrial and Earth-space communications including navigation satellite systems such as GPS, GLONASS and the future GALILEO system. The standard techniques to determine TEC are the Faraday rotation and the dispersive phase measurements. In general these techniques measure the electron content along a slant signal path from which the vertical TEC is found by simple geometric conversions.

The METU-NN modelling software referred to earlier in this paper has been used in the prediction of TEC. The TEC was derived from GPS signals as measured at Chilbolton (51.8 N, 1.26 W) during April and May in 2000 and 2001, with portions of this data used for the training, test and validation of the METU-NN. An additional validation was performed using an independent data set consisting of TEC values derived from GPS signals received at Hailsham $(50.9 \mathrm{~N}, 0.3 \mathrm{E})$ for selected months in 2002 (Tulunay et al., 2003). This study found that the METU-NN model could predict GPS-TEC one hour ahead on the validation set with an RMS error of 1.87 TEC units (which when normalised represents $7.26 \%$ ) with a cross correlation coefficient of 0.985 . An example of the predictions made by the tool on the validation set can be seen in fig. 3.16. The use of the METU-NN software for TEC prediction is described in more detail in another paper in this volume.

In general, the techniques used to find the TEC measure the electron content along a slant signal path from which the vertical TEC is found by simple geometric conversions. A new technique has been proposed by Reinisch and Huang (2001) to calculate the total electron content of the ionosphere up to $1000 \mathrm{~km}$ using vertical incidence sounding, so having the potential advantage that the vertical TEC is calculated directly. The method is designed to be used with ionosonde data, and is imple- 


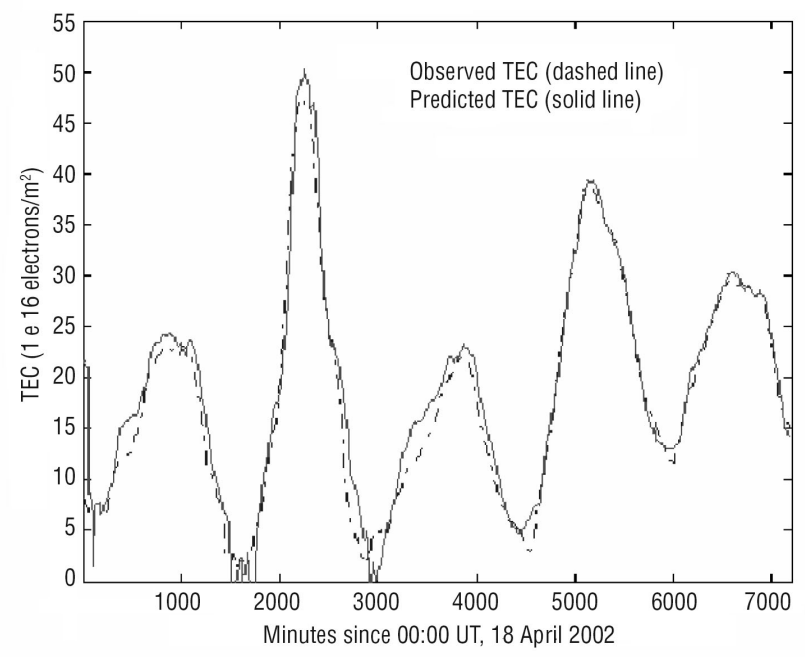

Fig. 3.16. Prediction of the GPS-TEC values from Hailsham on 18-22 April 2002, one hour ahead using the METU-NN model.

mented in the ARTIST software for automatically scaling ionograms that is supplied with the DPS Digisonde sounders manufactured by the University of Massachusetts, Lowell, Center for Atmospheric Research (UMLCAR). The ionogram provides the information to calculate directly the vertical electron density profile up to the the peak of the $F 2$-layer. The profile above the $F 2$ peak is approximated by an $\alpha$-Chapman function with a constant scale height $H_{T}$ derived from the bottom-side profile shape at the $F 2$ peak. This is determined by the equation

$$
N_{T}=N m F 2 \exp \left(\frac{1}{2}\left(1-z-e^{-z}\right)\right)
$$

where $z=\frac{h-h m F 2}{H_{T}}, N m F 2$ is the maximum electron density of the $F 2$-layer and $h m F 2$ is the height of the F2-layer peak. By integrating the combination of the bottom-side profile calculated from the ionogram inversion and the modelled top-side Chapman layer over the range from 0 to about 1000 $\mathrm{km}$ the 'Ionosonde TEC', ITEC, can be calculated.

Several studies have been carried out to investigate the properties of the ITEC parameter, comparing it with TEC values derived from GPS, incoherent scatter radar and geostationary satellite beacon measurements at middle latitudes and with TOPEX measurements at the equator, showing very good agreement (Reinisch and Huang, 2001; Belehaki and Tsagouri, 2002a), with the last of these finding that the top-side electron content amounts to roughly $2 / 3$ of the total ionospheric TEC. A subsequent study brought together experience within the COST 271 community on both ionospheric sounding and GPS-derived TEC to compare in detail the two methods of the calculating TEC values (Belehaki et al., 2003). This study consisted of a systematic comparison of ITEC and GPS derived TEC values estimated for the same geographic location.

GPS-derived TEC measurements (GPS-TEC) represent the electron content up to the altitude of GPS satellites, roughly $20000 \mathrm{~km}$, so correspond to the full atmospheric electron content of bottom-side and 

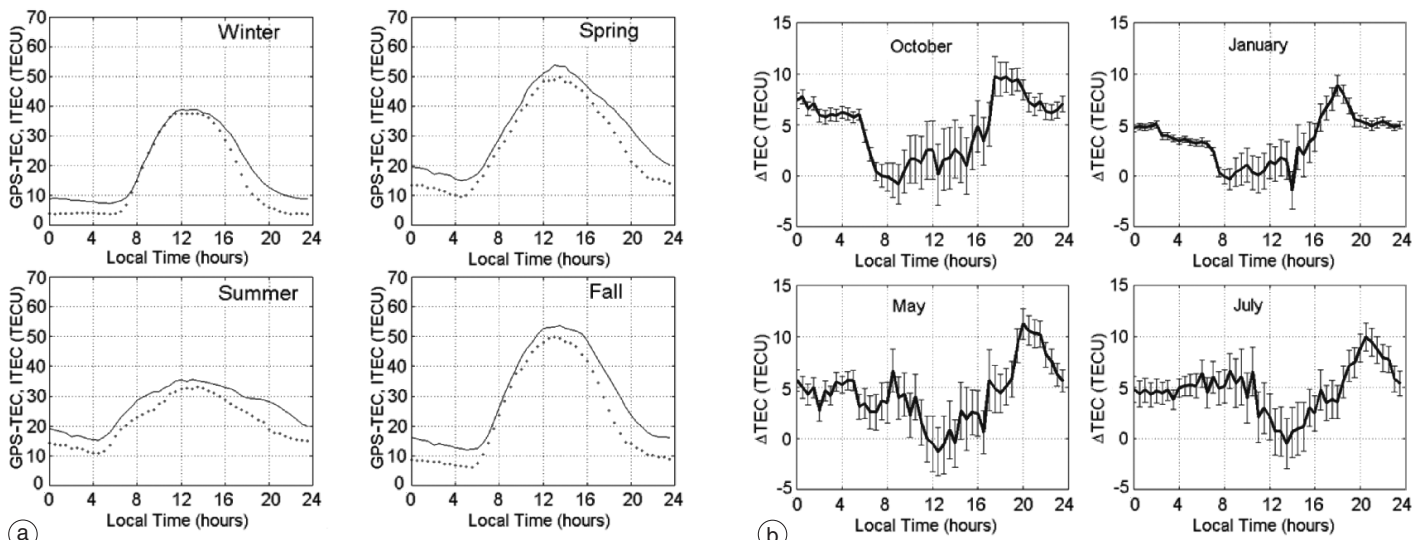

Fig. 3.17a,b. A seasonal comparison of GPS-TEC and ITEC, as observed at Athens during the period October 2000 to September 2001. a) The diurnal variation of GPS-TEC (solid lines) and ITEC (dotted lines) for the four seasons extracted from the mean of the monthly median values; $b$ ) the daily variation of the monthly median values of $\triangle \mathrm{TEC}$ over four months.

top-side ionosphere plus the plasmasphere. For the study, GPS-TEC maps produced by DLR/IKN for Europe were used, and the ITEC was calculated for the Athens digisonde. The comparison was made using data covering the 12-month period from October 2000 to September 2001 and showed a general agreement during daytime with a systematic deviation of ITEC towards lower values during the night.

This is illustrated by fig. 3.17a,b, which shows both the seasonal diurnal variation of GPS-TEC and ITEC, and the daily variation of the difference between them, $\triangle T E C$. The detailed analysis showed that

1) The diurnal variation of $\triangle T E C$ exhibits a morning minimum and an evening maximum, which can be explained in terms of ionospheric-plasmaspheric ionisation exchange. The prominent evening enhancement, observed in all seasons around 18:00-20:00 LT, can be attributed to the plasmaspheric bulge.

2) A superposed epoch analysis on the daily $\triangle T E C$ values for several geomagnetic storms showed a rapid decrease of $\triangle T E C$ just after the storm initiation and a subsequent increase over a time period of 9 days, a behaviour that is consistent with plasmaspheric depletion and successive replenishment following storm activity.

3) The daily variation of the ionospheric slab thickness is compatible with the daily variation of the thermospheric temperature. The behaviour of the total slab thickness is, however, affected by the nighttime increase, most prominent in winter, which is due to the lowering of the $\mathrm{O}^{+} / \mathrm{H}^{+}$transition height.

In summary, the difference between the ITEC and GPS-TEC values is entirely characteristic of the behaviour of the plasmaspheric contribution to the total electron content, lending strong support to the notion that ITEC is a good measure of the remaining ionospheric component of TEC, up to an altitude of $1000 \mathrm{~km}$.

\subsection{Conclusions}

This paper has presented some examples of the work carried out during the COST 271 Action targeted at improving forecasting, nowcasting and warning services. There have been developments at a number of levels: improving operational services such as the RWC Warsaw and the STIF 
service, the creation of new or experimental services such as the real-time ionospheric monitoring service from the RCRU at Chilton, advances across a range of fields covering modelling and data assimilation into models, and more basic research investigating the potential uses of a novel method of determining the crucial TEC parameter.

There are clearly many opportunities for continuing to develop the work described here:

- The RWC and STIF operational nowcasting, forecasting and warning systems will continue to be maintained and developed, responding both to the needs of users and to the new opportunities opened up by advances in computing, communications and instrumentation technologies.

- The currently experimental nowcasting facility provided by the RCRU will mature as experience of its behaviour grows. There are also plans to extend the range of the system, both in terms of its geographical coverage by including real-time ionosonde data from elsewhere in the world as determined by user demand, and in terms of including other parameters from the ACE dataset to improve the predictive capabilities.

- There is the potential to draw together the experience of the several teams developing methods for assimilating prompt data into regional ionospheric models. They have explored a variety of methods for adapting models using either ionospheric parameter values or height profiles, with the different methods exhibiting different characteristic strengths, and it may prove possible to employ two techniques simultaneously deriving benefit from both. There is also scope for integrating these adaptive models with databases of prompt data, creating the possibility of transforming these adaptive models into operational services.

- Underlying all the more operational services are models of ionospheric and space weather phenomena, with this paper referring to validation of the ITEC parameter, modelling the signature of global geomagnetic disturbances in the $K p$ index, and employing the flexible tool of neural networks. Continued development is clearly possible, for example to refine the inputs and training of the neural network models to improve their ability to forecast further into the future.

As a result of the work carried out during the COST 271 Action, significant enhancements have been made to the range and quality of forecasting, nowcasting and warning services available to users in the European area. There have also been advances in our understanding of how to model and predict the underlying ionospheric and geomagnetic phenomena, driven by the changing space weather environment, which determine the ionospheric propagation conditions. The success of this work is due in no small part to the collaboration fostered by the Action, and with a continuation of such collaboration it will be possible to make more progress in the years to come.

\section{ACKNOWLEDGEMENTS}

We would like to acknowledge the contributions made by all of our co-workers, whose names appear on the papers included in the reference list, and which describe more fully the work reviewed in this paper.

\section{REFERENCES}

Araujo-Pradere, E.A., T.J. Fuller-Rowell and M.V. Codrescu (2002): Storm: an empirical stormtime ionospheric correction model, 1. Model description, Radio Sci., 37 (5), 1070.

BELEHAKI, A. and I. TSAGOURI (2002a): Investigation of the relative bottomside/topside contribution to the total electron content estimates, Ann. Geophysics, 45 (1), 73-86.

BELEHAKI, A. and I. TSAGOURI (2002b): On the occurrence of storm induced night time ionisation enhancements at ionospheric middle latitudes, J. Geophys. Res., 107 (A8), 23,1-23,19.

Belehaki, A., N. JaKowski and B.W. ReINISCH (2003): Comparison of ionospheric ionization 
measurements over Athens using ground ionosonde and GPS-derived TEC values, Radio Sci., $36(6), 1105$.

BilitzA, D. (2001): International Reference Ionosphere 2000, Radio Sci., 36 (2), 261-275.

BilitZA, D. (2003): International Reference Ionosphere 2002: examples of improvements and new features, Adv. Space Res., 31 (3), 757-767.

Burešová, D., LJ. R. CANDER, A. VERnON and B. ZOLESI (2004): Results of real-time ionospheric $N(h)$ profile updating over Europe using IRI-2000 model, in Proceedings of the 3rd COST 271 Workshop, 23-27 September 2003, Spetses, Greece.

CANDER, LJ.R. (2003): Toward forecasting and mapping ionospheric space weather under the COST Actions, Adv. Space Res., 31 (4), 957-964.

CANDER, LJ.R. and L. CiraOlo (2002): First step towards specification of plasmaspheric-ionospheric conditions over europe on-line, Acta Geod. Geophys. Hung., 37 (2/3), 153-161.

CAnder, Lj.R., R.A. BAmFord and J.G. HickFord (2003): Nowcasting and forecasting the foF2, MUF(3000)F2 and TEC based on empirical models and real-time data, in IEE Conference Proceedings No. 491, vol. 1, 139-142.

CANDER, LJ.R., J.G. Hickford, I. TSAguri and A. BElehaKi (2004): Real-time dynamic system for monitoring ionospheric propagation conditions over Europe, Electron. Lett., 40 (4), 224-226.

De Franceschi, G. And L. Perrone (1999): Ionospheric and plasmaspheric modelling, in Improved Quality of Service in Ionospheric Telecommunication System Planning and Operation: COST 251 Final Report, edited by R. HANBABA (Space Research Centre, Warsaw), 105-107.

De Franceschi, G., L. Perrone, B. Zolesi and S. PaU (2000): The SWILM approach for regional longterm modelling of middle/high latitude ionosphere, Phys. Chem. Earth, 25, 343-346.

HoumineR, Z., J.A. BenNeTt and P.L. Dyson (1993): Real-time ionospheric model updating, J. Electric. Electron. Eng., Australia, 13 (2), 99-104.

Johnson, E.E., R.I. Desourdis, G.D. EARLE, S.C. CoOK and J.C. OstergaARd (1997): Advanced High-Frequency Radio Communications (Artech House, Boston and London, U.S.A.).

Karpachev, A.T., M.G. Deminov and V.V. Afonin (1996): Model of the mid-latitude ionospheric trough on the base of Cosmos-900 and Intercosmos-19 satellites data, Adv. Space Res., 18 (6), 221-230.

Kutiev, I. and P. Muhtarov (2003): Empirical modeling of global foF2 ionospheric response to geomagnetic activity, J. Geophys. Res., 108 (A1), 1021, doi:10.1029/2001JA009134.

LEITINGER, R. (1997): Reference ionospheric characteristics, Technical Report Recommendation ITU$R$ Series $P 1239$.

ReInISCH, B.W. and X. HuANG (2001): Deducing topside profiles and total electron content from bottomside ionograms, Adv. Space Res., 27 (1), 23-30.

STANISLAWSKA, I. and Z. ZBYSZYŃSKI (2001): Forecasting of the ionospheric quiet and disturbed fof2 values at a single location, Radio Sci., 36 (5), 1065-1071.

StANISLAWSKA, I., G. JUCHNIKOWSKI and Z. ZBYSZYŃSKi (2001): Generation of instantaneous maps of ionospheric characteristics, Radio Sci., 36 (5), 1073-1081.

StANisLaWSKA, I., H. RothKAEHL and D. BUREŠOVÁ (2004): Limited-area electron concentration height profile instantaneous maps, Adv. Space Res. (in press).

STANKOV, S.M. (2002): Evaluation of theoretical profilers used in the electron density profile reconstruction, Acta Geod. Geophys. Hung., 37 (4), 385-401.

StAnkov, S.M., I.S. Kutiev, N. JAKOWSKI and S. Heise (2002): Electron density profiles deduced from GPS-TEC, $\mathrm{O}^{+}-\mathrm{H}^{+}$transition height and ionosonde data, Acta Geod. Geophys. Hung., 37 $(2 / 3), 171-181$.

Stankov, S.M., N. Jakowski, S. Heise, P. Muhtarov, I. Kutiev and R. Warnant (2003a): A new method for reconstruction of the vertical electron density distribution in the upper ionosphere and plasmasphere, J. Geophys. Res., 108 (A5), 1164, doi:10.1029/2002JA009570.

StANKOV, S.M., R. WARNANT and J.C. JodOGNE (2003b): Real-time reconstruction of the vertical electron distribution from GPS-TEC measurements, Acta Geod. Geophys. Hung., 38 (4), 377-388. 
Tulunay, E., E.T. Senalp, Lu.R. Cander, Y.K. Tulunay and L. Ciraolo (2003): Forecasting GPSTEC during high solar activity by neural network technique, in Proceedings of the 2nd COST271 Workshop, 2-4 October 2002, Faro (Portugal).

Tulunay, Y.K., E. TulunaY and E.T. Senalp (2001): An attempt to model the influence of the trough on HF commmunication by using neural networks, Radio Sci., 36 (5), 1027-1041.

Zolesi, B., LJ. R. CANDER and G. DE FrANCESCHI (1996): On the potential applicability of the simplified ionospheric regional model to different midlatitude areas, Radio Sci., 31 (3).

Zolesi, B., A. BelehaKi, I. Tsagouri and LJ.R. CANDER (2004): Real-time updating of the simplified ionospheric regional model for operational applications, Radio Sci., 39 (2), RS2011, doi:10.1029/20003RS002936. 